\title{
FOSTERING CULTURAL DEVELOPMENT: FOSTER PARENTS' PERSPECTIVES
}

by

\author{
Ellice Daniel \\ Submitted in partial fulfilment of the requirements \\ for the degree of Master of Social Work
}

at

Dalhousie University

Halifax, Nova Scotia

April 2011

(C) Copyright by Ellice Daniel, 2011 


\section{DALHOUSIE UNIVERSITY \\ SCHOOL OF SOCIAL WORK}

The undersigned hereby certify that they have read and recommend to the Faculty

of Graduate Studies for acceptance a thesis entitled "FOSTERING CULTURAL DEVELOPMENT: FOSTER PARENTS' PERSPECTIVES” by Ellice Daniel in partial fulfilment of the requirements for the degree of Master of Social Work.

Dated: April 11, 2011

Supervisor:

Readers: 


\title{
DALHOUSIE UNIVERSITY
}

DATE: April 11, 2011

\begin{abstract}
AUTHOR: Ellice Daniel
TITLE: $\quad$ FOSTERING CULTURAL DEVELOPMENT: FOSTER PARENTS' PERSPECTIVES

DEPARTMENT OR SCHOOL: $\quad$ School of Social Work

DEGREE: MSW CONVOCATION: October $\quad$ YEAR: 2011
\end{abstract}

Permission is herewith granted to Dalhousie University to circulate and to have copied for non-commercial purposes, at its discretion, the above title upon the request of individuals or institutions. I understand that my thesis will be electronically available to the public.

The author reserves other publication rights, and neither the thesis nor extensive extracts from it may be printed or otherwise reproduced without the author's written permission.

The author attests that permission has been obtained for the use of any copyrighted material appearing in the thesis (other than the brief excerpts requiring only proper acknowledgement in scholarly writing), and that all such use is clearly acknowledged.

\footnotetext{
Signature of Author
} 


\section{Dedication Page}

I dedicate this thesis to my parents Jerome and Pronella Daniel because they have been behind me as well as beside throughout my academic journey. My siblings Monique, Jason, Vonnette, Bridget, and Brian for their love, support and inspiration. To my partner Patrick, for his encouragement, my cousin José as well as my friends Benita, Cecilia, Jessica, Karlan, Michelle, Phebe, and Sasan who have been there to see me through this endeavour. 


\section{Table of Contents}

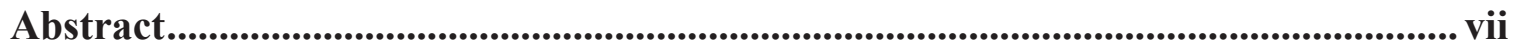

List of Abbreviations Used ....................................................................................... viii

Acknowledgements ................................................................................................................... ix

Chapter 1 Introduction..................................................................................................... 1

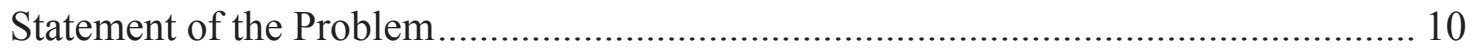

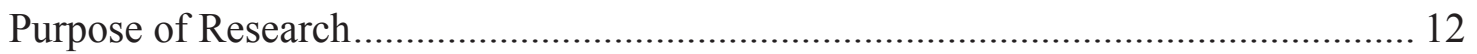

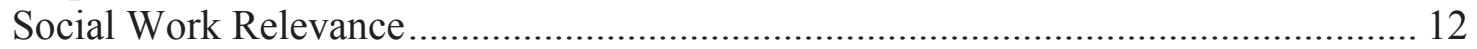

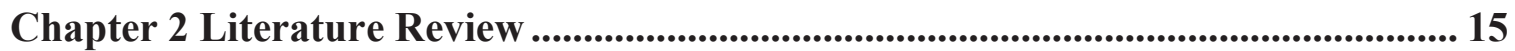

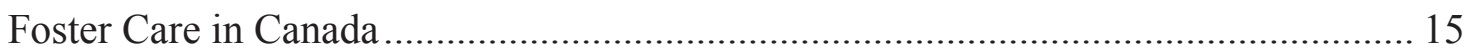

Prevalence of Transcultural Foster Care Placements................................................... 17

Potential Impacts of Transcultural Foster Care Placements ......................................... 17

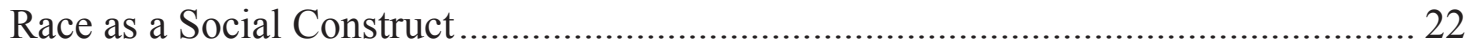

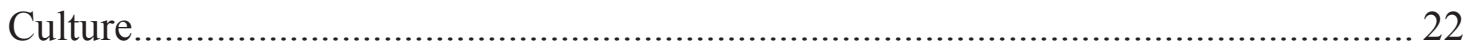

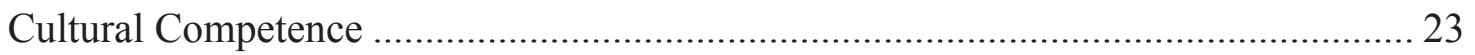

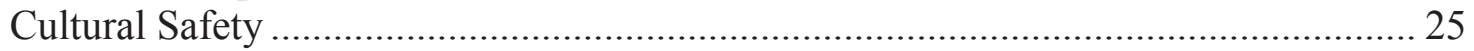

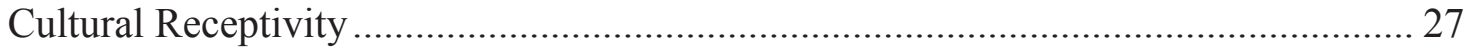

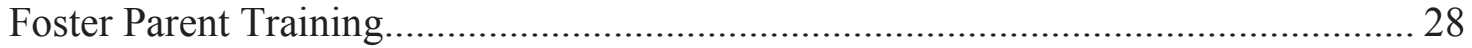

Barriers to Obtaining Training ................................................................................. 29

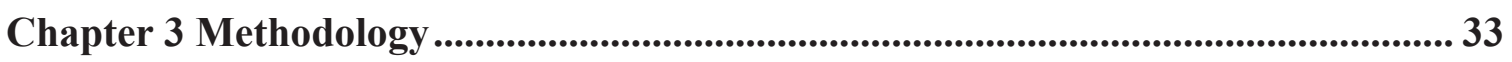

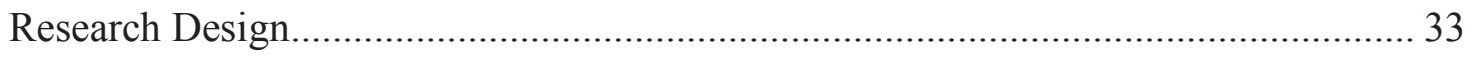

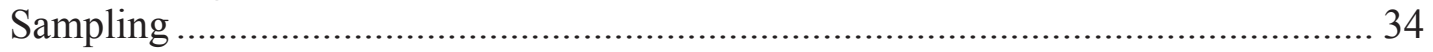

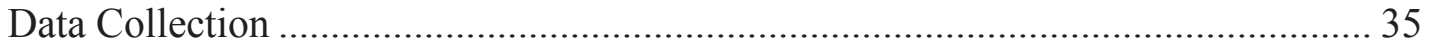

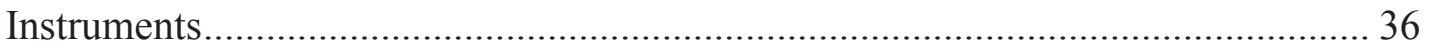

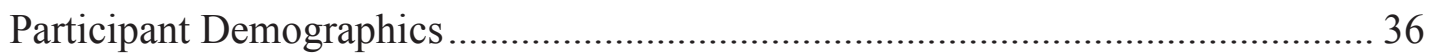

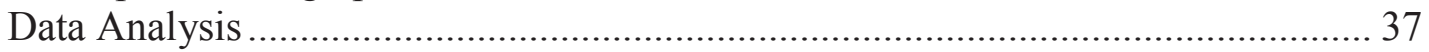

Strengths and Limitations ............................................................................... 39

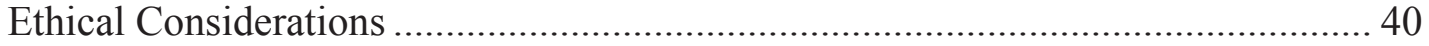

Chapter 4 Results................................................................................................................ 42

Engaging Knowledge with Personal Experience ......................................................... 42

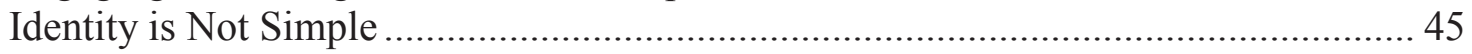

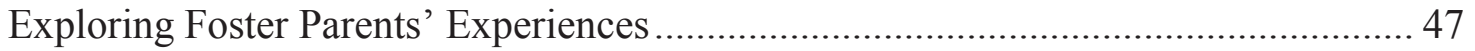

Transcending 'Race' in Foster Homes................................................................... 47

Importance of Recognizing Differences ................................................................. 48

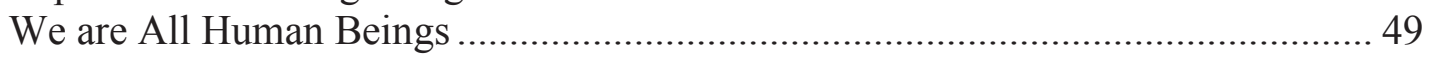

Experiences of Discrimination.............................................................................. 50

Value of Establishing and Maintaining Relationships............................................... 51

Using Racialized Identities to Negotiate Household Rules ...................................... 53

Strained Familial Relationships ........................................................................... 54

Foster Homes Engaging in Cultural Development ……………................................. 55

Increasing Cultural Awareness in Foster Homes ....................................................... 59

Limitations and Challenges Foster Parents Faced ......................................................... 61 


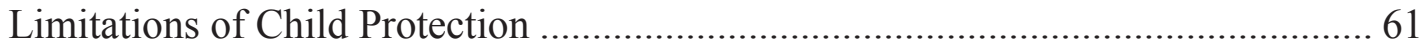

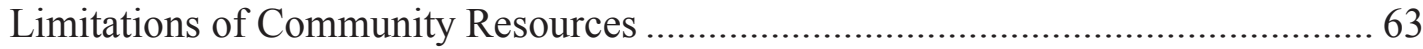

Limitations of Child Protection Confidentiality Policies........................................ 64

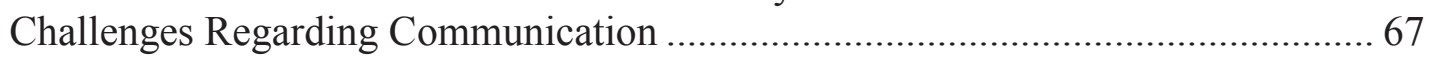

Challenges Regarding Child Protection Workers' Attitudes .................................. 68

Advice for Foster Parents and Child Protection Agencies...................................... 71

Advice for Foster Parents....................................................................................... 71

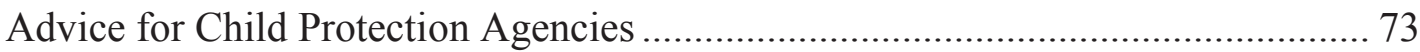

Fostering Cultural Development...................................................................... 76

Chapter 5 Discussion .......................................................................................... 78

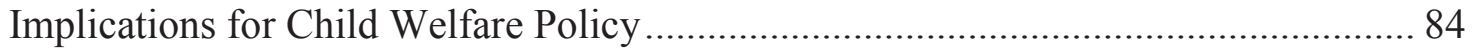

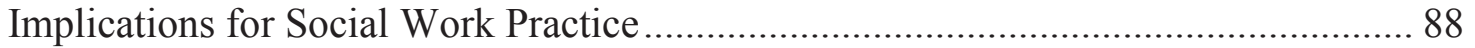

Chapter 6 Conclusion ................................................................................................. 90

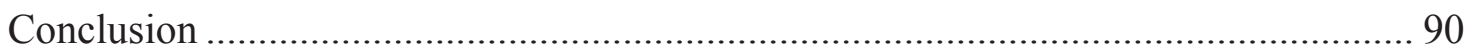

Recommendations for Future Research ........................................................... 92

References ...................................................................................................................... 94

Appendix A Demographic Questionnaire..................................................................... 103

Appendix B Interview Guide ............................................................................................... 106 


\begin{abstract}
Given the increased number of children from racialized groups requiring foster care and the decreasing number of foster parents from racialized groups, transcultural foster placements are on the rise. Addressing racial and cultural diversity within the context of transcultural foster care placements is one of the most pressing dilemmas of contemporary child protection practice, in Canada. In this qualitative exploratory study, the perspectives of regular non-kinship foster parents groups in Nova Scotia and British Columbia, Canada, who provide foster care to children and youth from racialized groups, were explored through open-ended structured interviews. Participants consisted of nine foster parents, between the ages of 30 and over 60 years old, who were asked to share their experiences regarding transcultural foster care placements. The results of this study indicated foster parents were culturally receptive and 'fostering cultural development' in their homes as well as their respective communities.
\end{abstract}




\section{List of Abbreviations Used}

$\begin{array}{ll}\text { ABSW } & \text { Association of Black Social Workers } \\ \text { PRIDE } & \text { Parent Resources for Information, Development, and Education program }\end{array}$ 


\section{Acknowledgements}

First and foremost I would like to thank the Lord above for blessing me with the opportunity to pursue and complete a graduate degree. I want to express my deepest appreciation to my parents Jerome and Pronella Daniel who have continually and consistently supported my educational endeavours. I thank my family for their support over the years and particularly during this exciting phase of my life. Without them, this thesis would not have been possible. I thank my partner, Patrick Pemberton, for his love, support and understanding that helped me as well as motivated me to achieve this milestone. I look forward to our journey together as this one comes to an exhausting end.

I also thank my thesis committee my supervisor Dr. Catrina Brown, reader Dr. Wanda Thomas-Bernard and external reader Dr. Adrienne Chan. Their support and encouragement kept me focused on the end goal and encouraged me to pursue this thesis

without doubting the outcome. Without the support from them this thesis would have felt impossible.

Thank you to my research instructor, Jeff Krabanow, who helped me believe in my ability to complete a thesis. To all my friends, I would like to say thank you for being there for me and believing in me.

Lastly, I would like to thank foster parents who participated in this study for taking the time to share their stories with me. Their responses were reflective of the unyielding commitment they have to children and youth from racialized groups in their care. 


\section{Chapter 1 Introduction}

According to the Centre of Excellence for Child Welfare (2010), a foster home is a private home approved by child welfare services for the placement of children in need of protection. The focus of this research is on regular non-kinship foster parents, involved in transcultural foster care placements. Regular non-kinship foster parents provide substitute parenting in foster homes for children in the charge, care, custody or guardianship of the provincial government and these foster parents have not previously known these children (Province of British Columbia, 2010, Province of Nova Scotia, 2010). For the purpose of this research, a transcultural foster placement occurs when children and youth from racialized groups are placed with foster parents from a different racial or cultural background than the children.

Children and youth from racialized groups include those who are Aboriginal and who are non-Caucasian in race or non-white in color. According to Vickers (2002), the term racialized refers to "the political and ideological processes by which populations are linked to physical characteristics" (p. 190) and socially constructed as racially distinct, primarily based on a manifestation of unequal power between groups (Baum, 2006).

Historically 'white' populations, such as the Italians, have also experienced the processes of racialization by being excluded from immigration policies and assigned menial employment (Vickers, 2002). However, for the purpose of this research, children from these groups were not included in the definition of children and youth from racialized groups.

This thesis sought to explore cultural receptivity as it relates to foster parents and how they promoted the culture development of children and youth from racialized groups. 
Cultural receptivity involves a foster parent's openness to encourage children's relationships with people who share their cultures, find resources where these children can go to get their cultural needs met, learn about parenting strategies from the children's cultures, and learn from other people who have parented children from racialized groups (Coakley et al., 2006). Cultural development involves the process whereby children acquire knowledge rooted in their birth culture to form behaviours, social skills, and cognitions that help them thrive in their world (Super \& Harkness, 1986).

Since little research exists, to date, that includes the voices of foster parents involved in transcultural foster placements within the context of cultural receptivity; this study was both relevant and unique. Within transcultural foster care placements, both foster parents and children and youth from racialized groups can have unique needs that arise during the placement. These needs may coalesce around cultural development, identity formation, as well as establishing or maintaining relationships children and youth, from racialized groups, have with their families of origin. Additionally, these needs may be impacted by the availability of resources and support offered through child protection agencies or the lack thereof.

I anticipated foster parents would offer clues about policy and practice implications that affect the cultural development of children and youth from racialized groups. Moreover, I hoped to discover potential opportunities for changes and improvements in practice, policy, and training for foster parents. Furthermore, I wanted to contribute to the gap in knowledge about strategies and supports required for foster parents, to promote the cultural development of children and youth from racialized groups. Understanding how foster parents, involved in transcultural foster placements promote the cultural 
development of children and youth from racialized groups, in their care is central to this study because of my own personal experiences of racism and discrimination in Canada, as well as my professional experience as a Social Worker.

I am a Black Canadian who was born to immigrant parents from the Caribbean. I grew up in British Columbia, with both of my biological parents, in a household with my five older siblings. Being the youngest of six children, I was the last person, in my family, to experience the cruel racist taunts from classmates, neighbors and members in society.

As a child, I heard stories from my parents about the racism they faced in their respective workplaces. I also heard stories from my siblings about the racist experiences they were subjected to at school. I struggled to make sense of their experiences from my sheltered position as the youngest.

It was not until I was in the fifth grade that I had my first experience with racism. I remember it as if it was yesterday. I was on the playground, in the sand box, being compared to cat feces in a litter box. In that moment, I recall feeling alone. I also recall feeling as if I could now relate to the experiences of the other members in my household. Ironically, this provided comfort for me because, I felt, no other children on the playground understood my painful experience. Fortunately, discussions about race and racism were a common occurrence in my household, as a child. Since my parents were immigrants from the Caribbean, our discussions were typically situated within the context of their culture.

In elementary school, the influence of my parents Caribbean background meant that I was constantly being questioned about the foods I brought for lunch, the way my hair was 
braided, the reason why my working parents could not participate in field trips or why my parents spoke the way they spoke. As a child, I did not have answers. I would often go home to the protective walls of my family, distressed and looking for explanations and support. Thankfully, my parents and siblings gave me answers. They armed me with ammunition and armor to combat the racist experiences I started to be subjected to, in a world that I perceived as cruel.

The remainder of my elementary and high school years consisted of me longing to be anything but Black. I wanted to have silky blond hair with blue eyes and eat the foods that other kids ate at lunchtime. I hated my parents' Caribbean accents and I wanted them to speak the same way the other kid's parents spoke. I did not want to be the only Black kid in all my class. Most importantly, I felt cheated because I felt that I was missing something all of the other kids had. I wanted to feel as if I belonged somewhere other than in my house, with my family.

It was not until the age of 17 years old that I found friends who looked like me, could relate to me and did not question me. From that moment on, I felt 'normal' because I had friends to talk to and hang out with. I could invite them over for dinner without having to explain the foods we ate, the music we listened to or the way we lived. I started to venture off into the world with my friends who became my allies. I started exploring my experiences and tried desperately to make sense of them. While reading the book $W e$ real cool Black men and masculinity, written by bell hooks, I read a quote that resonated with my experiences and I remember it to this day. She wrote:

There are not healthy benefits to being Black, sexy or more beautiful in a society run by Whites who resent and feel challenged by your beauty, who are obsessed with controlling or dominating you in reaction to the self-consciousness they feel in your presence...This is a precarious place to be. (p. 83) 
This quote helped me to understand the pain I felt as a child. It also made me appreciate the fact that I had a family who could relate to me, educate me and protect me. I cannot imagine how frightening my experiences could have been, if it were not for my family.

Since the age of 19 years old, I have worked with individuals who have come into contact with the criminal justice system. My career began with the Provincial Government of British Columbia when I was hired, as a Correctional Officer, in a maximum security remand centre. While I was employed in this position, I decided to pursue a degree in Social Work in order to become a Probation Officer to work with individuals on probation in the community. After being a Probation Officer for a few years, I gained employment with the Provincial Health Services Authority, at an adult outpatient forensic psychiatry clinic, where I am currently employed as a Social Worker.

Over the course of my career, I have had conversations with individuals that revolved around the circumstances that led to their involvement with the criminal justice system. The majority of their narratives had a common theme stemming from their childhood. Amongst a variety of unique narratives, embedded within these stories were descriptions of substance misuse or traumatic childhood experiences causing separation from their biological families, and expressions of loneliness.

A major theme was that many individuals were removed from the care of their biological parents and were involved with child protection agencies. Some of these individuals also had children who had been involved with child protection agencies. More specifically, in some cases, individuals would share stories about their parents' illicit substance misuse that resulted in them being removed from their biological parents care and entering the foster care system. Following numerous placements between foster 
homes, group homes or relatives, some individuals started using illicit substances to cope with their situations. While active in their addiction cycle, many individuals committed criminal offences which resulted in incarceration.

As a result of their incarceration, they shared stories about being separated from their own children who were subsequently placed in the foster care system. In most cases, there were not opportunities to place their children with their relatives, because of their relative's histories of substance misuse. In such cases, their children were often times made permanent wards of the Court. Similar to their parent's upbringing, they became involved in the tumultuous nature of the foster care system or adopted which, at times, resulted in familial connections being severed.

Over the course of my professional career, I have seen the impact of these severed familial connections in a variety of ways. Some individuals have chosen to remain disconnected from their families or cultures of origin. Moreover, individuals have decided to refrain from attempting to establish or maintain relationships with their families or the resources available to them in their communities of origin. For example, I worked with a woman, of South Asian descent, who had painful childhood experiences that affected her in adulthood. She explained to me, she had no desire to re-connect with her biological family or culture of origin because she worked tirelessly to overcome her painful childhood memories.

Other individuals have been affected because of the lack of information about their families of origin. Moreover, information about their families of origin provides critical information for completing comprehensive social histories and mental health assessments. Accordingly, having accurate information about their families of origin can 
assist in identifying any psychiatric or medical conditions that may be relevant to assessing their treatment needs.

One particular story contributed to my interest in the foster care system. I was working with a young man, of Aboriginal descent, who was place in the foster care system. He was abandoned by his biological mother, who had a history of substance misuse, and found in a hotel room at 10 weeks old. He was adopted shortly thereafter and raised by the same family until the age of 14 years old. Unfortunately, when his behaviour became too unmanageable for his adoptive family, he was placed in the foster care system and eventually became involved with the criminal justice system. As a result of one of his convictions, he was placed on probation with a condition to attend my place of employment, for an assessment and treatment of any identified mental health concerns.

When I interviewed him, he could not provide any details about his family of origin. He told me there had been queries, during his childhood, made about whether or not he had Fetal Alcohol Syndrome/Effect. He explained this diagnosis could not be confirmed or ruled out because they did not have any information about his biological mother. In terms of accessing services, a formal diagnosis was required to obtain funding for appropriate services to meet his needs.

Additionally, the absence of this information prevented him from accessing specific funding and services because they could not trace his blood line back to a particular Band. It also limited my ability to complete a thorough assessment of his mental health, because he could not provide any information about the psychiatric history of his family of origin. Unfortunately, this was the case for many individuals I worked with in jail, on probation and at the adult outpatient forensic psychiatry clinic. Based on these 
narratives, I foresee similar experiences for children of some of the clients I work with, if child welfare policies are not adjusted to circumvent these familiar stories.

Reasonably, my interest in foster parents, the foster care system and children and youth from racialized groups materialized through both my personal and professional experiences. Although I have never been in foster care or worked directly in a child protection agency, I experienced racism in my childhood and work with individuals who have current or past experiences with child protection agencies. The potential impact of racism on children and youth from racialized groups, in the foster care system, is difficult to measure because of the confidential and private nature of child protection.

Additionally, I believe children in the foster care system, particularly children and youth from racialized groups, are one of the most vulnerable groups in Canadian society because they receive minimal support from child protection agencies.

Addressing racial and cultural diversity in social work practice is one of the most pressing dilemmas of contemporary child welfare practice. Racial considerations in child welfare are highly political, regardless of how careful the conceptualization or design of the approaches to the issue (Korbin, 2002). Therefore, it is critical to gain knowledge regarding foster parent's understanding of cultural receptivity, to provide insight into the factors that affect the cultural development process of children and youth from racialized groups, in foster care. This understanding provides useful information that can be considered when developing policies, establishing best practices, required supports, recruitment and retention strategies.

Furthermore, this understanding may provide useful information for program development to reduce or avoid placement breakdowns, possibly contributing to 
increased retention rates and decreased attrition rates. In order to train foster parents and efficiently distribute scarce child protection agency resources, these agencies need "systematic information about which activities and services are associated with foster parent retention" (Rhodes et al., 2001 p. 86). According to Twigg (2009), until the needs of foster parents are met we will continue to struggle with the challenges of recruiting and retaining qualified foster parents. Since foster parents are the front line of service delivery, their perceptions are important to "determine how best to improve the responsiveness of the system" (Brown \& Calder, 1999 p. 482).

This study found foster parents' personal and professional experiences as well as their exposure to diverse communities, contributed to how they viewed children and youth from racialized groups and how they promoted cultural development. According to foster parents I interviewed, having children and youth from racialized groups in their homes was a rewarding experience for themselves as well as their own families.

The challenges foster parents faced were primarily a culmination of the attitudes and behaviours of child protection agency workers, child protection agency policies, lack of training opportunities and limited resources within their communities. These challenges typically resulted from the specific circumstances of children and the logistics of working within the confidential and protective parameters of child protection agencies.

Based on their experiences, foster parents provided advice for existing as well as future foster parents involved in transcultural foster care placements. They also made recommendations for child protection agencies to improve their current practice and modify existing policies, such as confidentiality, that interfered with their ability to promote the cultural development of children and youth from racialized groups. 
The core theme that emerged through qualitative data analysis was that foster parents were 'fostering cultural development'. This theme reflects the isolated efforts foster parents made to promote the cultural development of children and youth from racialized groups. Foster parents, in this study, were culturally receptive and committed to finding opportunities to integrate culture into the lives of children and youth from racialized groups. Unexpectedly, the individual efforts foster parents made simultaneously increased cultural awareness within their own families and households.

Consistent with the existing literature, foster parents in this study, reported not having the support of child protection agencies when making decisions about culturally relevant resources, activities and relationships. The results of this study can be useful when developing child welfare policies, establishing best practices for child protection workers, identifying required supports as well as recruitment and retention strategies for child protection agencies.

\section{Statement of the Problem}

Although there is available research on foster parents, most of this research comes from the United States and Britain, with a lack of current data on foster parents in Canada, within the context of race and cultural. Yet, an overrepresentation of Aboriginal, African American, Hispanic, and other children from racialized groups in the Canadian foster system is well documented (Elliott \& Urquiza, 2006; Freisthler, Bruce, \& Needell, 2007; Harris \& Hackett, 2008; Trocmé, Knoke, \& Blackstock, 2004). Given the increased number of racialized children requiring foster care and the decreasing number of foster parents from racialized groups, transcultural foster placements are on the rise. 
Children from racialized groups, coming into foster care, have specific needs related to cultural development that foster parents must support. The cultural development process, for children placed in transcultural foster placements, is different than children raised in racially and culturally homogeneous families. As such, foster parents must be willing and able to seek out resources as well as opportunities, in their respective communities, to promote the development of foster children's cultural and racial identities (Vonk, 2001).

Understanding how cultural values, beliefs and traditions of foster parents are related to promoting cultural development is critical because a substantial proportion of children in foster care are from racialized groups. Foster parents, fostering children and youth from racialized groups, have unique needs and may require assistance to address the cultural differences within their home and communities.

Unfortunately, foster parents are facing increasing demands on their time, resources, and skills, as the needs of the children in foster care they are being asked to provide care for increase and as the scrutiny they endure by the placement agency, the government, and the general public increases (Twigg, 2009). Its stands to reason that the need to provide adequate training and support for foster parents increases, as the needs of children entering the foster care system may be culturally specific.

Foster parent training programs have been developed to create awareness and to assist foster parents in meeting the needs of children and youth from racialized groups. However, due to limited resources or the lack of available relevant training, foster parents do not always obtain support and resources related to promoting the cultural development 
of children and youth from racialized groups. At the same time, the effectiveness of these programs has not been evaluated.

\section{Purpose of Research}

The purpose of this qualitative exploratory research study was to explore how regular non-kinship foster parents, in Nova Scotia and British Columbia involved in transcultural foster placements, promote the cultural development of children and youth from racialized groups, including those who are Aboriginal and who are non-Caucasian in race or non-white in colour. In this study, the perspectives of foster parents, who provide foster care to children and youth from racialized groups, were explored through openended structured, in-person or telephone, interviews.

The interview questions were organized around their opinions regarding the available training, their understanding of cultural receptivity, the challenges as well as the limitations they faced, their experiences of racism or discrimination, the resources available to them, and the advice they would offer to future foster parents. These questions were useful in order to gain an understanding of what foster parents did and what they needed to assist them in promoting the cultural development of the children and youth from racialized groups, in their care.

\section{Social Work Relevance}

This study provides information regarding the ways in which foster parents promote the cultural development of children and youth from racialized groups in foster care. Moreover, this information contributes to the gap, in the body of existing knowledge, regarding foster parents who provide foster homes for children and youth from racialized groups involved with child protection agencies. It also identifies useful information 
related to the needs of foster parents who provide foster care services to children and youth from racialized groups.

This study gave foster parents an opportunity to share their stories, opinions and ideas while expressing the challenges they faced as foster parents involved in transcultural foster care placements. Participants contributed valuable information that can be used to improve future relationships with the child protection agencies. The results of this study, offer insight into how child protection agencies can better meet the needs of foster parents, which may subsequently impact the cultural development of children and youth from racialized groups in foster care. This understanding can assist in developing policies, establishing best practice, required supports as well as recruitment and retention strategies. This understanding also provides useful information for program development to reduce or avoid placement breakdowns, which could lead to increased retention rates and decreased attrition rates.

The implications arising from this research are beneficial to policy makers, child protection agencies as well as social workers, caregivers, and researchers who are committed to promoting the cultural development of children and youth from racialized groups. This information contributes new knowledge regarding how foster parents promote the cultural development of children and youth from racialized groups involved with child protection agencies, in Nova Scotia and British Columbia.

Following chapter one which included the statement of the problem, the purpose of the research and the relevance to social work practice. Chapter two reviews the existing literature regarding foster care, foster parents, race, culture and approaches use in practice to address diversity. Chapter three describes the research methodology and Chapter four 
presents the findings of the research. Chapter five includes a discussion of the findings. Finally, chapter six presents the researcher's conclusions regarding how foster parents promoted the cultural development of children and youth from racialized groups, including the implications for child welfare policy as well as social work practice and recommendations for future research. 


\section{Chapter 2 Literature Review}

This literature review examines foster care in Canada, the prevalence of transcultural foster care placements, race as a social construct and culture. It also examines the potential impacts of transcultural foster care placements, foster parent training, culture competence, cultural safety, cultural receptivity, and barriers to foster parents obtaining training.

\section{Foster Care in Canada}

In Canada, child protection law and enforcement are the responsibility of each province and territory. Children and youth are deemed to be in need of protective services when there is a family crisis or allegations of physical, sexual or emotional abuse or neglect, substance abuse, parent/adolescent conflict, death of a parent/parents or abandonment. As a result of investigations into these allegations, some children and youth cannot remain in their family homes, and find their way into out-of-home care and, most often, into foster care. Therefore, foster homes exist out of need and child protection legislation sanctioned by the provincial government and are a major service provider (Twigg, 1991) providing as much as 60 percent of out-of-home care (Gibbs \& Wildfire, 2007; Wilson, Sinclair, \& Gibbs, 2000).

Accordingly, for many children, foster care is not short term and many end up residing in multiple foster homes over the course of their lives. Moreover, children in foster care of every age may never return home nor be adopted (Barth, 1990) making these children one of the most vulnerable groups in Canada. The vulnerability of children from racialized groups is further compounded by their reliance on the commitment and best 
practices of the provincial government policies as well as agencies to protect and promote their well-being.

In Nova Scotia, according to Section 20 (d) of the Child and Family Services Act (1990), when placing a child in a foster home, an agency shall ensure the child's best interests are served, taking into account the preservation of the child's cultural, racial and linguistic heritage, when practical. Similarly, in British Columbia, when deciding where to place a child, the director must consider the child's best interests according to Section 4 (1) of the Child, Family and Community Service Act (1996).

Accordingly, Section 4 (1) (e) of the Child, Family and Community Service Act (1996), indicates that the child's cultural, racial, linguistic and religious heritage must be considered in determining the child's best interests. In particular, if the child is an Aboriginal child, the importance of preserving the child's cultural identity must be considered in determining the child's best interests. Moreover, according to Section 71 (3) (b) if the child is an Aboriginal child, the director must give priority to placing the child with another Aboriginal family.

When these policies hinder the ability to provide placements for children from racialized groups, the screening process is often expedited resulting in transcultural foster placements. Moreover, placements are often made based on the availability of foster parents rather than on an appropriate fit between the background, experience and skills of foster parents and the needs of the children (Price, Chamberlain, Landsverk \& Reid, 2009). As a result, too often in practice the need to place a child overrides the need to find a foster family that can meet the needs of a child from a racialized group. 


\section{Prevalence of Transcultural Foster Care Placements}

Research indicates there is an under-representation of foster parents from racialized groups and an overrepresentation of children from racialized groups in North American foster care (Bradley \& Hawkins-Leon, 2002). For example, across Canada, it is estimated that $40 \%$ of children in care are Aboriginal, but make up less than $17 \%$ of the general population (Farris-Manning \& Zandstra, 2003). Another example is in an urban centre of Ontario, where the Black population totals $8 \%$ and Black youth represent $65 \%$ of the youth in group care (The Child Welfare Anti-Oppression Roundtable, 2008 revised 2009).

As a result, approximately $45 \%$ of foster parents report caring for children from a different racialized background than their own (Coakley \& Orme, 2006). By the nature of the composition of these families, children from racialized groups experience different childhood experiences around issues related to race and culture (Baden \& Steward, 2000), than children from non-racialized groups. Particularly, when a child from a racialized group has to leave their birth family and move in with a Caucasian family, there will be cultural differences that both parties need help understanding, no matter how loving the foster family (Coakley \& Buehler, 2008).

\section{Potential Impacts of Transcultural Foster Care Placements}

According to Carter-Black (2002), one of the most notable problems occurs when Caucasian foster parents disregard the importance of race. Without a family and community that are sensitive to these issues and able to facilitate a healthy transition, a racialized child could become confused about their identity (Chipungu \& Bent-Goodley, 
2004). Moreover, a culturally sensitive environment can provide a nurturing and protective foundation that racialized children can draw upon in times of distress.

In fact, DuMont, Widdon and Czaja (2007) found that individual characteristics as well as the fit between an individual and his or her environment are important in understanding resilience. Furthermore, several studies found that a placed child's wellbeing or self-concept can be supported or enhanced by maintaining close contact with their extended family and cultural heritage (Burnette, 1999; Christenson \& McMurtry, 2007; Kruger \& Powell, 1990).

Children and youth from racialized groups, coming into foster care, have specific needs related to cultural development that foster parents must support. Cultural development refers to the process whereby children acquire knowledge rooted in their birth culture to form behaviours, social skills, and cognitions that help them thrive in their world (Super \& Harkness, 1986). The cultural development process, for children placed in transcultural foster care placements, is different than children raised in racially and culturally homogeneous families. Subsequently, the children within these racially and culturally integrated families need foster parents who are willing and able to support their needs.

Within transcultural foster care placements, the cultural development of these children could be jeopardized if foster parents are unwilling or unable to address their specific racial or cultural needs. For the past 30 years, the National Association of Black Social Workers (2010), which has a Canadian chapter in Nova Scotia called the Association of Black Social Workers (ABSW), has maintained the importance of finding culturally 
appropriate options for children of African ancestry before giving consideration to placing these children outside of the community.

ABSW established a Placement Committee in order to express concerns regarding child welfare legislation, identify child welfare policies and practices that may adversely affect Black children in care and respond to any problem areas relative to the foster placements of Black children. According to their position statement titled Placement issues concerning Black children, dated January 1989, ABSW recognizes the Black family as the most effective resource for survival that Black people have and opposes child welfare practices of placing Black children in homes with white foster parents.

Moreover, ABSW subscribes to the belief that Black children should "grow in a safe, secure environment with parents who are able to transmit to that child a positive sense of culture, identity and well-being" (ABSW Placement Committee, 1989 p. 1). Furthermore, ABSW “adheres to the position that Black children be placed in Black homes where they belong physically, psychologically and culturally in order that they receive a total sense of themselves and are free to develop to their fullest potential" (ABSW Placement Committee, 1989 p. 2).

The available literature indicates children and youth from racialized groups are frequently placed with foster parents from non-racialized groups. Therefore, it is less likely a child or youth from a racialized group will be placed according to the ABSW's position statement. Although there may be benefits to placing children and youth from racialized groups with foster parents from racialized groups, there are additional factors that are not static and evolve continuously that contribute to the cultural development as well as identity formation of children and youth from racialized groups. 
Anti-oppressive theory emphasizes that we "do not occupy a single social identity; rather, the social groups to which we belong are heterogeneous rather than homogeneous" (Strega 2007 p. 72). Factors such as gender, race, culture, socio economic status, education level, age, ability and sexual orientation can privilege a person's access to power or resources while restricting others from marginalized group's access to power and resources (Strega, 2007). For example, the experiences of people from marginalized groups and the identities they develop based on their experiences, can uncover the daily operation of oppression (Baines, 2007). Subsequently, placing children and youth from racialized groups, who tend to be from marginalized groups, with foster parents from non-racialized groups who typically have access to power and resources creates unique dynamics.

Floyd (2009) found that former foster youth, who were interviewed in adulthood, had unique attitudes toward their experiences of racialized socialization. Participants in that study reported receiving inconsistent or contradictory racialized messages from their families, foster parents and professionals, making the development of a positive racialized identity difficult. According to Bernard and Este (2005), "having a positive racial identity is a strategy that helps black boys negotiate their space and location in society as they journey to manhood" (p. 449).

Unfortunately, children and youth in care may find themselves ostracized from the racialized as well as the non-racialized social worlds and find it difficult to fit in either environment. Audet and Home (2003) found that families of ethnically different children were also subject to marginalization and were constantly asked inappropriate questions or were stared at because they were "a standout, quickly recognized family" (p. 163). 
In transcultural foster care placements, significant challenges, for foster parents, concern their knowledge, practice and comfort in meeting the unique needs of foster children who come from racialized groups. Particularly, among families that are visibly different from many other families, foster parents benefit from becoming more aware of how racism and discrimination impact their family and children from racialized groups in foster care as well as strategies to mitigate the effects (Vonk, 2001). de Haymes and Simon (2003) found that foster parent's confidence and practice in dealing with the perceptions of others about their motives to foster, the response of their own extended family members to the child, and combating racism in their community could be effectively enhanced through participation in training.

Accordingly, any discussions about the services children from racialized groups in foster care receive would be incomplete without highlighting issues of social injustice in the context of institutional racism and discrimination. Regrettably, "racism and discrimination toward young African Canadian males is even more prevalent in Canadian institutions such as the educational, legal and social service systems where members of this group are likely to be victims of racial profiling” (Bernard \& Este, 2005 p. 34).

The impact of social injustice, racism and discrimination, in addition to the need to develop skills for negotiating a sometimes hostile social world, cannot be discounted because the impact can distinctly shape an individual (Chipungu \& Bent-Goodley, 2004). For example, the ability to function within the larger non-racialized community as well as within a specific racialized community is an important survival skill for children from racialized groups. Subsequently, teaching racialized children how to navigate through 
conflicts related to race is a skill that can be difficult to acquire from people outside of the racialized community (Chipungu \& Bent-Goodley, 2004).

\section{Race as a Social Construct}

The concept of 'race' has been deeply involved in constructing and rationalizing inegalitarian social relations since it was introduced in the seventeenth century (Baum, 2006). Some social scientists view race as a social construct (Better, 2008; Kirton, 2001; Parker \& Song, 2001) with harmful effects, while recognizing that racialized identities can be an important mobilising force for those struggling against discrimination and disadvantage (Parker \& Song, 2001). According to Baum (2006) understanding race in terms of racialization avoids any reification of racial difference because it emphasizes the historically changing and politically contingent nature of the process of racialization.

\section{Culture}

According to Better (2008), a social construct is a culturally determined idea therefore race, must be understood within the context of culture. However, culture is not static and cannot be viewed as being uniformly distributed or having a uniform impact on all members (Korbin, 2002). Culture is "a complex whole that includes knowledge, values, beliefs and other capabilities and habits of people" (McGibbon \& Etowa, 2009 p.65).

Thus, a static definition reduces culture to sets of enduring traits (Korbin, 2002) and encourages broad generalizations and stereotypes that do not allow for the constant transformation that people and societies undergo (Mederos \& Woldeguiorguis, 2003). Moreover, a fluid definition of culture allows for change and attention to individual differences while recognizing the lasting influence of certain experiences (Mederos \& 
Woldeguiorguis, 2003; Yee \& Dumbrill, 2003) and set the stage for more sensitivity and sophistication in service provision (Mederos \& Woldeguiorguis, 2003).

While maintaining the idea that culture is not static, it is necessary, "to unpack culture to understand how it works in all of its complexity" (Korbin, 2002 p. 638). The postmodernist understanding of culture is that all cultural identities are socially and historically constructed and, therefore, changeable in response to different internal and external contingencies (Williams, 2006). Accordingly, postmodern cultural 'competence' involves exploring the collection of identities and experiences that produce continually evolving, unique cultural experiences for clients (Dean, 2001).

\section{Cultural Competence}

Nonetheless, modernist cultural competence has been a construct on which programs related to diversity have been based. Cultural competence is defined as "a set of congruent behaviours, attitudes, policies, and structures that come together in a system or agency or among professionals and enables the system, agency, or professionals to work effectively in cross cultural situations" (Cross et al, 1989 p. 7). Cultural competence can be conceptualized as consisting of four components which are cultural awareness, the affective dimension; cultural sensitivity, the attitudinal dimension; cultural knowledge, the cognitive dimension, and cultural skills, behavioural dimension (Rew, Becker, Cookston, Khosropour \& Martinez, 2003).

The concept of cultural competence denotes working with cultural groups other than one's own (Korbin, 2002) and "the ability to transform knowledge and cultural awareness into health and/or psychosocial interventions that support and sustain healthy clientsystem functioning within the appropriate cultural context" (McPhatter, 1997 p.261). 
Within the context of the foster care system, it has been used to meet children's unique racial and cultural needs (Vonk, 2001). However, cultural competence may not be an appropriate construct because competence in a specific cultural group is likely not transferable between individuals, families, and communities (McGibbon \& Etowa, 2009).

Moreover, some researchers (Pon, 2009; Sakamoto, 2007) feel it promotes an outdated view of culture and is a form of racism. According to Pon (2009), cultural competence is similar to the processes involved in racism by means of "otherizing non-whites and by deploying modernist and absolutist views of culture to promote racialized and stereotypical views of cultural groups without ever having to use racialist language" (p. $64)$.

As an attempt to encourage cultural sensitivity, the perceived cultural differences may promote stereotypes and reinforce the concept of 'others' while perpetuating the idea that certain behaviours should be controlled and adjusted to resemble norms of the dominant group (McGibbon \& Etowa, 2009). For example, this approach assumes that cultural groups have stable identities, creating harmful stereotypes such as "Africans believe this..." "Mexicans believe that..." (McGibbon \& Etowa, 2009 p. 76). Consequently, these groups continue to be denied the realities of systemic racism, discrimination as well as other forms of social disparities and blamed for their difficulties (McGibbon \& Etowa, 2009). Additionally, Dean (2001) views the concept of cultural competence as flawed. She argues that cultural competence assigns membership, into cultural categories, to particular aspects of identity such as race or ethnicity which are viewed as static and endure over time. 
One of the challenges of using a cultural competence model is that it operates at an individual level, by applying specific techniques and skills based on a person's perceived knowledge about a particular culture. In a diverse society, people choose between various cultural options and widely between the options offered by a variety of cultural traditions. This approach does not capture the diverse, fluid and complex nature of culture as well as self-identity. Moreover, it may attempt to predict the beliefs and behaviours of people based on a person's race or culture.

Since it is not possible to predict how a person from a particular culture self identifies, a person's group membership cannot be assumed to indicate their culture. Moreover, stagnant definitions of culture fail to effectively address diversity, within membership to a cultural group, leaving minimal space for cultural change. Consequently, such an approach may inadvertently place blame on a person's culture. It may also emphasize cultural differences which can obscure structural power imbalances, on an institutional level.

Cultural competence does not reach far enough in addressing institutionalized oppressions. It can leave those working from this approach, unequipped to deal with institutional racism and oppression, where it permeates, on structural and global levels. Moreover, it only reifies existing racial categories rather than deconstructing systemic factors that contribute to racism, discrimination and oppression. Despite the widespread application of cultural competence, to promote organizational practices to meet the needs of diverse populations, it remains a vaguely defined goal, due to the elusive nature of its central construct, which is culture.

\section{Cultural Safety}


Another approach to diversity has been developed in New Zealand called cultural safety. According to Richardson and Carryer (2005), this approach prepares nursing students to develop culturally safe nursing practice in the New Zealand health care environment and is unique to New Zealand. Moreover, it involves teaching nursing students to recognize and understand the dynamics of cultural, personal, and professional power and how these shape nursing and health care relationships (Richardson \& Carryer, 2005).

Unlike cultural competence, which is an imported paradigm derived from a multicultural context which can essentialise group members, cultural safety goes beyond describing the practices of other ethnic groups (Richardson \& Carryer, 2005) because this political, structural and social approach focuses on health professionals' behaviours and institutional responses rather than the clients they provide service to (DeSouza, 2008). Applying the concept of cultural safety means:

To think and learn about how the status of the minority culture gives rise to the care needs of the people of that minority - how their care needs necessarily reflect the socially structured inequalities that have been shaped by their historical, political and economic realities (Zon, Lindeman, Williams, Hayes, Ross and Furber, 2004 p. 289).

Conversely, according to Polaschek (1998) the concept of cultural safety has been criticised for being a general concept that "does not address the societal dimension directly apart from individual influences (p. 454).

Both culture competence and cultural safety are approaches that were designed to sensitize care providers to the specific needs and vulnerabilities of members from a particular cultural group, with the goal of increasing awareness and providing appropriate care. Consequently, both approaches focus on knowledge of individual aspects, from a 
particular culture, without recognizing the structural factors contributing to racism, discrimination and oppression. Both approaches need to involve structural changes in organizational and systemic factors that contribute to racism, discrimination and oppression. Therefore, culture competence and cultural safety do not appear to be the most effective approaches to training foster parents involved in transcultural foster care placements.

The focus of contemporary approaches to working with foster parents, involved in transcultural foster care placements, should focus on highlighting the ongoing processes of seeking out resources and building relationships (Dean, 2001). In keeping with the view that race is a social construction and culture is a collection of identities that produce continuously evolving experiences, a similar approach to recruiting, assessing and training foster parents should be taken. Accordingly, the conceptual framework underpinning this research study is cultural receptivity.

\section{Cultural Receptivity}

Cultural receptivity looks at foster parent's willingness to seek training, support, and services to increase their transcultural foster parenting abilities. According to Coakley and Orme (2006), cultural receptivity measures foster parents' openness toward participating in activities that support the cultural development of children in foster care from racialized groups.

Specifically, it involves foster parents openness to encourage children's relationships with people who share their cultures, find resources where children can go to get their cultural needs met, learn about parenting strategies from children's cultures, and learn from other people who have parented children from racialized groups (Coakley \& Orme, 
2006). Despite the differences in opinion, research has documented the importance of cultural receptivity in fostering and has shown that cultural receptivity can be enhanced through training (Baden \& Steward, 2000; Coakley \& Buehler, 2008; Coakley \& Orme, 2006; Cross et al., 1989; de Haymes \& Simon, 2003; Massatti et al., 2004; Vonk, 2001; Vonk \& Angaran, 2001).

\section{Foster Parent Training}

The content of many foster parent training efforts is related to helping participants understand children's development while preparing them for anticipated difficulties that may occur during their foster care situation (Baum, Crase \& Crase, 2001). In Nova Scotia, foster parents are required to attend the Parent Resources for Information, Development, and Education program (PRIDE). This program includes a six hour module on cultural competence (Province of Nova Scotia, 2010). Similarly, in British Columbia, foster parents are required to attend the Foster Care Education Program which includes a three hour module on cultural awareness (Province of British Columbia, 2010).

According to Christenson (2006, as cited in Christenson \& McMurtry, 2007), the PRIDE pre-service training program has been implemented in more than 23 states and provinces within North America. However, the development of a comprehensive, longterm, empirically based evaluation model of this program has not been developed (Christenson, 2006, as cited in Christenson \& McMurtry, 2007).

Furthermore, very little evidence exists concerning the extent to which prospective or practicing foster parents possess such skills, to which the widely used training program PRIDE imparts these skills, or to which these skills lead to successful outcomes for the children placed in the care of foster families (Orme \& Buehler, 2001; Vonk, 2001). 
Although foster parents are required to participate in training such as PRIDE, it has been documented that only a few foster parents actually receive post licensure training on working with teens, children who had been sexually abused, children with disabilities, and children of a different race then that of the foster parents (Brown et. al., 2009; Rhodes, Orme \& Buehler, 2001).

\section{Barriers to Obtaining Training}

Opportunities for foster parents to attend additional training to enhance the well-being of racialized foster children is often limited or denied in some cases. For example, oongoing training for foster parents is often hampered by many factors such as lack of resources, scheduling problems, transportation issues, access to respite care in order to attend training, and a lack of priority given to training by the foster care system (Twigg, 2009). Consequently, foster parent's limited access to material resources creates challenges within the fostering relationship.

Significant challenges, for foster parents, concern their knowledge, practice and comfort in meeting the unique needs of foster children who come from racialized groups. de Haymes and Simon (2003) found that foster parent's confidence and practice in dealing with the perceptions of others about their motives to foster, the response of their own extended family members to the child, and combating racism in their community could be effectively enhanced through participation in training. Particularly, among families that are visibly different from many other families, foster parents benefit from becoming more aware of how racism and discrimination impact their family and racialized foster children as well as strategies to mitigate the effects (Vonk, 2001). 
Unfortunately, as a result of having limited access to material resources and increasing demands, only a small percentage of foster parents actually receive post licensure training on working with children of a different race than that of the foster parents (Rhodes et al., 2001). The unique needs of racialized foster children involved in these types of placements are compromised because their foster parents are not able to attend programs or there is lack of commitment to provide adequate training and resources to foster parents.

In a Canadian study conducted by Brown, St. Arnault, George and Sintzel (2009), foster parents were aware of the need for culturally specific resources in the system, such as pre and post-placement services as well as counselling from a non-dominant cultural approach. They felt such services should be provided by individuals from children's cultures or with sufficient awareness of their culture as well as situated in close proximity to their community. Foster parents in this study felt a culturally sensitive foster care system would help them address the gap in knowledge, experience and practice within transcultural foster care placements (Brown et al., 2009). Brown et al., (2009) also found that transitions for foster parents and children in foster care, as they learn to live together, are crucial points for culture-based interventions.

Additionally, these foster parents described a need for training on culture and ways to approach differences between them and their foster children who were from a different background (Brown et al., 2009). These foster parents felt their confidence would be enhanced through practice and a safe place to discuss how they were feeling about and handling differences. 
They also felt their confidence would be enhanced developing strategies to manage disagreements and promote understanding in their own families and communities about how their foster children see the world around them (Brown et al., 2009). Based on their findings, they concluded foster parents wanted opportunities to learn about how their values, beliefs and traditions contribute to how they fulfill their role as foster parents and how the experiences of the children who come into their care are similar to and different from their own (Brown et al., 2009). The findings, from this study, were consistent with the literature on cultural competency.

To summarize, within the context of child protection, social constructions of race and culture create challenges with potential impacts on children and youth from racialized groups in foster care. Approaches to foster parent training programs have been developed to assist foster parents; however the effectiveness of these programs has not been evaluated. Based on the literature reviewed, regarding foster parents within the context of race and culture, it appears an approach that includes components of culture; racial awareness, multicultural planning, and survival skills for children and youth from racialized groups would be ideal for children in care, foster parents and child protection agencies (Vonk \& Angaran, 2001).

This chapter reviewed some of the existing literature on foster care within the context of transcultural foster care placements. The review of the existing literature demonstrates a lack of information regarding how foster parents promote the cultural development of children and youth from racialized groups. This research study was developed to explore cultural receptivity and the experiences of foster parents involved in transcultural foster care placements. The following chapter outlines the methodology of this thesis including 
the research design, sampling, data collection, instruments, participant demographics, data analysis, the strengths and limitations as well as the ethical considerations. 


\section{Chapter 3 Methodology}

\section{Research Design}

The research design was exploratory in nature and used social constructionism to discover themes related to the experiences of regular non-kinship foster parents, involved in transcultural foster placements. Social constructionism recognizes the social, historical, political and interpersonal processes involved in the construction of knowledge and "cannot be separated from human meaning-making processes" (Brown \& AugustaScott, 2007 p. xv). In contrast, constructivism focuses on individual interpretations that create knowledge and meaning. The emphasis in this research, however, recognizes that social interaction and processes are involved in the construction of knowledge. From this view, "knowledge is always culture bound" (Brown \& Augusta-Scott, 2007 p. xv). In this study, I explored the narratives of participants with the understanding that their stories are not simply individual, but part of the larger context of social meaning.

Social meaning is exchanged, created and reproduced through social interaction within specific social and historical contexts. The stories that people tell then relies on the social construction of knowledge and meaning. The narrative lens emphasized in this study maintains that "we do not and cannot, create our stories by ourselves" (Brown \& Augusta-Scott, 2007 p.xix). Furthermore, stories emerge only within a social context of meaning because "meaning cannot exist independent of social life" (Brown \& AugustaScott, 2007 p. xix).

By using a modified grounded theory approach, I began with the experiences of foster parents and explored how they construct it by gaining multiple views and locating themes in "its web of connections and constraints" (Charmaz, 2006 p. 187). Modified grounded 
theorists acknowledge they are part of their constructed theory and their "theory reflects the vantage points inherent in our varied experiences, whether or not researchers are aware of them" (Charmaz, 2006 p. 149). While Charmaz (2006) describes her modified ground theory methods as constructivist, I used a social constructionist approach. Using a social constructionist approach allowed me to extend the constructivist framework to include a more politicized exploration of foster parents involved in transcultural foster care placements and issues of racialization.

I chose this theoretical framework because it depends on my view as the researcher and looks at how "participants construct meanings and actions in specific situations" (Charmaz, 2006 p. 130). I also took a "reflexive stance" toward the research by interpreting the meanings and actions of myself, as the researcher, and participants (Charmaz, 2006 p. 131). Using this modified approach, I acknowledged that what I saw and did not see, throughout this research study, rests on values and I am aware of how my starting assumptions affected this research (Charmaz, 2006). Overall, the constructionist approach to my participant's knowledge allowed me to situate their stories about fostering children and youth from racialized groups, within the larger social structure in which those stories emerge. Neither race, nor fostering are neutral social concepts. Thus, the methods of this study allowed me to recognize the political and social ramifications of transcultural foster care placements.

\section{Sampling}

Purposive sampling was used to select participants for this study. Eligible participants met the following criteria: a) a regular non kinship foster parents, b) current or past experience in transcultural foster placement c) a racial or ethnic background that was not 
the same as the youth or children from racialized groups and d) a willingness to share their experiences openly and honestly. This inclusion criteria was selected because the children placed in these homes are not known by the caregiver (Province of Nova Scotia, 2010; Province of British Columbia, 2010) and because these foster parents have been approved by Agency and District Office staff to provide care to children and youth (Human Resource and Skills Development Canada, 2010). Data was gathered in Nova Scotia and British Columbia, Canada, between August and December 2010.

Participation in this study was voluntary, and the participants were notified that all the information and collected data would be kept confidential. To ensure anonymity and confidentiality, participants were asked to choose a pseudonym so they remained unidentifiable in the reported data. Additionally, as I used snowball sampling techniques, participants were asked to advise any other eligible participants to contact me if they were interested in participating in the research project. Each participant was given the opportunity to enter their name in a raffle for a $\$ 50$ Chapters gift card for participating in the study.

\section{Data Collection}

Data was collected through open ended structured in-person or telephone interviews. Those interested in participating in the project were asked to contact me via email or telephone. I contacted interested participants in order to provide them with additional information about the study and discuss the consent form which outlined the purpose as well as the design of the research, confidentiality, risks and benefits. Participants decided on a date, time and location convenient to them, to conduct the interview. 
Prior to conducting interviews, participants were given the opportunity to ask questions or seek clarification regarding the study and their participation in the study. Participants were also advised they could withdraw their consent to participate at any time and they could refrain from answering any questions they did not feel comfortable answering. With participants' written informed consent, interviews were audio recorded. The audio recordings were transcribed and immediately destroyed upon completion of this process. In accordance with the University Policy on Scholarly Integrity, the written transcriptions will be shredded after five years post publication.

\section{Instruments}

I developed a demographic questionnaire (Appendix A) which captured the profile of participants in this study. I also developed a qualitative structured interview guide (Appendix B) which ensured all participants were asked the same questions, in the same order, to obtain consistent data. The questions were designed to provide participants with the opportunity to elaborate on their experiences as foster parents involved in transcultural foster care placements. Participants were asked questions regarding the training they received, cultural receptivity, the impact on their families, the challenges they faced, resources available to them, how comfortable they were seeking out support as well as the advice they would offer foster parents.

\section{Participant Demographics}

A total of nine foster parents were interviewed between the ages of 30 and over 60 years old. Participants were not asked to provide their exact ages but the majority of participants indicated they were over 60 years old. Of those interviewed, seven foster parents were female and two were male. Seven foster parents indicated they were 
married while two indicated they were single. The education level of the participants varied from the completion of $11^{\text {th }}$ grade to the completion of a doctoral degree. Two participants worked full time outside the residence, three worked part time outside the home and four participants were not employed outside of their residence. The annual household income of participants ranged considerable from $\$ 30,000$ to $\$ 150,000$ and the majority of participants indicated their annual household income was between $\$ 50,000$ and $\$ 70,000$.

One participant identified as Black, one participant identified as Aboriginal and the remaining seven participants identified as White. Those who identified as White further described themselves as a belonging to a variety of heritage groups such as Acadian, British, Cree, English, Estonian, Inuit, Irish, Jewish, Polish and Scottish. The years of experience this group of foster parents had ranged considerably from two months to 41 years. The estimated number of children in care they collectively provided care for also ranged from two to 300 children. Specifically, this group of foster parents estimated caring for one to 100 or more children and youth from racialized groups.

\section{Data Analysis}

Qualitative research involves building patterns, categories and themes from the bottom up by organizing data into more abstract units of information (Creswell, 2007). According to Charmaz (2006) "constructivist grounded theory lies squarely in the interpretive tradition" and studies how participants construct meanings and actions in specific situations (p. 130). I will add to this by extending my analysis to the larger social context, in which individuals construct meaning. The data consisted of eight hours and 40 minutes of in-person and telephone interviews which were transcribed verbatim. 
Immersion in the transcribed data allowed me to sort, code, compare and interpret the responses from participants which characterized a modified grounded theory approach.

Codes and categories were sorted, compared and contrasted until the analysis produced no new codes or categories and when all the data were accounted for in the core categories of the grounded theory paradigm model (Creswell, 2007). Open coding was the first step in data analysis which involved taking the data and placing it into categories. Line-by-line coding was used to gain a closer look at what participants said and lead to the development of theoretical categories (Charmaz, 2006). The code and category labels were guided by the language of the participants and were identified with short descriptors of their experiences (Creswell, 2007).

The next step in data analysis was axial coding, which organized the data in new ways and made connections between the categories and subcategories (Creswell, 2007). During axial coding the data was assembled into a coherent whole following line-by-line coding that was conducted during open coding (Charmaz, 2006).

Further analysis revealed that the individual efforts foster parents made subsequently increased cultural awareness within their homes with their own families. Foster parents indicated their lives and their families were enriched by being exposed to different cultures and participating in a variety of culturally relevant resources. These resources included culturally relevant activities, relationships, and events which were sought out by foster parents, on their own. The majority of foster parents reported child protection agency workers did not have a great deal of involvement, in facilitating connections to culturally relevant resources. 


\section{Strengths and Limitations}

This study was limited by the relatively small number of foster parents who participated. Since this study was exploratory in nature, the findings are not appropriate to form any generalizable conclusions (Faulkner \& Faulkner, 2009). However, it provides a narrow in depth examination of the experiences of foster parents providing foster care to racialized children and youth in two Canadian provinces.

Additionally, foster parents who participated in this project provided valuable information that can be used to improve future relationships with child protection agencies. Moreover, it provided useful information, regarding recruitment and training, for child protection agencies and foster care organizations to address the needs of foster parents involved in transcultural foster care placements. Furthermore, insight was gained into how these agencies can better meet the needs of foster parents and children from racialized groups in care in the future.

My own racialized identity was both a strength as well as a limitation in this study. It was a strength because participants, who were interviewed in person, may have felt comfortable discussing matters related to race with a person from a visibly racialized group. At the same time, it was a limitation because participants may have provided socially desirable responses since they were being asked to give personal accounts of their experiences. Socially desirable responses refer to the phenomenon in which individuals tend to answer questions according to what they perceive is more socially acceptable and not what they actually think, feel or believe (McGibbon \& Etowa, 2009). Subsequently, they may have groomed their responses in order to avoid offending the 
researcher or come across as racially or culturally insensitive. Unfortunately, this could have limited the depth of the responses obtained from foster parents.

A final limitation in this study was the absence of the opinions of children, from racialized groups, residing in transcultural foster homes. Future research could include the opinions of these children which may provide useful information regarding how the cultural receptivity of foster parents affected their cultural development. Additionally, the input from policy makers, child welfare workers, biological parents, and other major stakeholders was absent and would have strengthened the analysis of this issue.

\section{Ethical Considerations}

This research project was approved by the Social Sciences and Humanities Research Board at Dalhousie University. Subsequently, participants were recruited in accordance with Dalhousie Guidelines and the Tri-council Policy Statement on Ethical Conduct in Research Using Human Subjects. Participants were recruited through agencies that deal with extremely sensitive and private child protection matters and interviews were conducted in their respective communities. Due to the private nature of child protection, safeguarding the anonymity and confidentiality of participants was of paramount importance.

The anonymity and confidentiality of participant's responses were protected throughout the process of this study. I ensured participants signed a consent form and any identifiable information was kept separate and could not be linked to a particular participant. Obtaining informed consent and ensuring participants signed the required consent form helped to ensure the participants understood their rights as subjects in the 
study. Participants were also advised that I was required, by law, to report any information regarding any children or youth at risk.

The information collected through the demographic questionnaire and the interviews were of a personal and sensitive nature. To ensure anonymity and confidentiality, participants were asked, prior to beginning the interview, to choose a pseudonym. Non identifiable information was stored on my password protected laptop and any information gathered was secured in a locked filing cabinet. I was the only person who had a key to this filing cabinet.

This chapter outlined the research design, sampling, data collection, instruments, participant demographics, data analysis, strengths and limitations as well as ethical considerations. This research design allowed me to explore and document the experiences of foster parents involved in transcultural foster care placements. The proceeding chapter describes the seven themes that emerged from the data that was collected through qualitative interviews. 


\section{Chapter 4 Results}

This study explored the experiences of foster parents, involved in transcultural foster care placements, providing foster care to children and youth from racialized groups. A qualitative research design was used to offer foster parents the opportunity to share their experiences, within transcultural foster care placements. Foster parents, in this study, provided invaluable information regarding the efforts they made to promote the cultural development of the children in their care. They welcomed me into their lives, by sharing their time, knowledge and experience involved in promoting the cultural development of children and youth from racialized groups. The findings are based on ideas presented in the literature as well as the experiences of foster parents who participated in the research. The themes that developed through data analysis were supported by direct quotes from the interviews that were conducted and are described below.

\section{Engaging Knowledge with Personal Experience}

An important theme that developed during axial coding was 'engaging knowledge with personal experience'. Foster parents expressed a variety of views regarding how effective they felt the training, they were provided, prepared them for transcultural fostering. They thought their personal and professional experience had a greater impact on preparing them to work with children and youth from racialized groups.

There were some foster parents who had not received any training to prepare them for working with children and youth of racialized groups. They had not received training because formal training was not available when they began fostering over 30 years ago. One participant told me: 
When we started doing it we had no training bottom-line. Yeah so our preparation for taking on children of color, it just happened.

(Nez Bleu, Nova Scotia)

Other foster parents were frustrated because they had not received training due to child protection agency issues such as: agency turmoil, high turnover rates, maternity as well as sick leaves and lack of follow through by child protection agency workers. A participant, in a remote community, said:

We do have a wonderful training list of what they want to give us, if they ever give it to us. They have been working on getting it up and going for about a year.

(Suzy, British Columbia)

A small number of foster parents found the training they received helpful. They said: Because I have fostered for so many years, the ongoing training that we have received has taught me the new ways of doing things with children. Everything from trauma and stress and all the things regarding the children...The training keeps you up to date.

(Nana, British Columbia)

It taught us how to be sincere to the problems they have and how to comfort them.... find the training is good.

(Cindy, Nova Scotia)

Foster parents shared a variety of opinions regarding the training they received to work with children and youth from racialized groups. However, the majority of foster parents, I interviewed, thought the training they received was either not helpful or they had no recollection of the training. Some of the responses I heard were: 
I would say no it has not really prepared us for fostering children and youth of color. It was very cursory. It is not in depth, it does not really give you the knowledge or even a good understanding of the resources available in the community for dealing with children of color or youth of color.

(Joe, Nova Scotia)

I guess it has not made much of an impact because I cannot really recall how specific they were with it. Obviously that piece of the training did not really have an impact on me. From a personal level, I would engage myself prior to so if it was families who had not had exposure with working with various cultures then it would be more important for them to be aware of the importance of that.

(Cheryl, Nova Scotia)

Foster parents also indicated their own personal experiences, the education they received through university or the training they received through their employment was more helpful in terms of preparing them to work with children and youth from racialized groups. One foster parent told me:

The training was sort of a wider broader net that was thrown a lot wider and covered a lot more territory and did not really dig down deep enough. The education that we received at university and our personal experiences of living in really diverse communities, like in Scarborough Ontario and some of our travels and stuff that we have had in our lives. That probably did a lot more to prepare us for... you know just appreciating diversity, being sensitive to diversity, being aware. But yeah I would say the training did not...my personal experience that would be the most helpful.

(Meggie, Nova Scotia) 
They also told me stories about how beneficial the knowledge they gained, by involving the children's extended family members, was for the children in their care. A participant told me:

I have had wonderful relationships with the parents, grandparents and great grandparents. It helps me as the foster parent because you learn a little bit more about the children and what the parents...like grandma is the one who taught me ['Awa'] instead of 'no'. It helps the social workers if I have got a good working relationship with the parents or grandparents because there is not so much anger.

(Nana, British Columbia)

\section{Identity is Not Simple}

'Identity is not simple' was a significant theme that emerged during axial coding. Despite their training, personal experiences or exposure to racialized groups; foster parents consistently highlighted the complex nature of identity development in the children they cared for. For example, one woman told me:

The foster parenting...I think they just look at it as generalizations so that a child who comes in who is say African American and I am talking North American is sort of viewed in the same light as a Caucasian child. In some ways it is helpful because then it is not like you are treating anyone differently, and in some ways it is hurtful because you are not treating anyone differently. I look at it as accepting a person for who they are and where they are at right now. And of course a lot of kids do not realize that they are this descent or that descent. I had a little African American [Black Canadian] child and she did not realize she was Negro.... and my adopted son he had an African American speech language pathologist who he 
called my chocolate friend and the rest of us are plain vanilla.

(Helen, British Columbia)

Meggie, from Nova Scotia, described the inherent complexities involved with fostering children from parents who have immigrated to Canada. She said:

The divide is not just between us sort of the white parents and three black kids. The divide is also in between the kids. Kind of cool and complicated by the fact that black, in quotation marks, is not their only identity....Ethiopian kids, their dad is from northern Ethiopia and their dad spoke Arabic...and the youngest one now questions am I really Black or am I Muslim? Is my identity Black or is my identity Brown?

Meggie explained that she did not have a definitive answer to these types of questions because she did not really know what to say. She described having the following conversation:

We know your dad is from that area and we do not know. It is kind of like your choice... what do you feel resonates with you? This stuff is all basically a construct so pick your construct.

She further explained:

That was one of the first conversations I had with her about cultural identity. It was first time I had seen her a bit excited about cultural identity. For the first couple of years she was in our home she really wanted to suppress and deny cultural identity. She did not want to be identified by her last name and she did not want to be identified by African birth. She did not want to be at school when they do the introductions. She would refuse to tell them her last name or where 
she was born. She would refuse to tell them anything about her that would identify her as different or unique or whatever. It has only been broadly, within the last year that she has started to explore this stuff in an enthusiastic kind of way as opposed to a...oh god do not tell me. So even if I am encouraging these kids and trying to foster a Black consciousness, I am also kind of doing it with an awareness that their cultural, racial identity is a lot more complicated. It is not just Black, there may be a certain Muslim identity that will resonate with them or that is somewhere in their family perhaps. With these kids there is no simple identity.

(Meggie, Nova Scotia)

\section{Exploring Foster Parents' Experiences}

Exploring foster parents' experiences of having children and youth from racialized groups highlighted the unique dynamics within the homes of foster parents. There were a variety of experiences that impacted how foster parents promoted the cultural development of children and youth from racialized groups.

\section{Transcending 'Race' in Foster Homes}

This theme highlighted the experiences that may affect foster parents awareness and approach to promoting the cultural development of children and youth from racialized groups. One participant captured the essence of this issue. She said:

You do kind of forget because you are more concerned about the personality development and the healing and the attachment. You have got way big big issues of healthfulness that seem to transcend race but then it kind of always comes back. Which maybe would never happen if we had had three white kids in 
the house?...In some respects there is no such thing as a culturally appropriate foster home because there is not a single foster home that is going to replicate that family culture. To some degree, given the nature of apprehension and the nature of how kids come into care, it is a bloody good thing because that family culture is abuse and neglect and nasty stuff.

(Meggie, Nova Scotia)

Another foster parent indicated having children from racialized groups, in his home, was the closest he had ever been to a member of a racialized group. He stated:

It is the closest that I have ever been to a Black person. Like living with them in my home and everything like that. So it has been in a way affirming of the idea that color at the bottom of it does not really matter. But I know it does cause it is cultural and everything like that....We are all human beings as well and that fundamentally kind of pervades through everything and it certainly has raised my awareness of cultural and race issues, but I do not know to a great degree because we were pretty aware of it before.

(Joe, Nova Scotia)

\section{Importance of Recognizing Differences}

Other foster parents acknowledged the importance of recognizing differences in the way, in which, individual's parented children. They thought it was important to consider, not only, children's cultural backgrounds but also foster parents parenting style. A foster parent told me:

I guess if you are going to do it you have to have the interest in learning about different cultures and accepting of them. But not necessarily just the cultures, 
every family is different. I raised my children totally different than the lady next door so I think you have to be accepting of everything and want to learn.

(Nana, British Columbia)

Another foster parent said:

I am trying to plant my certain values in them. But the reality is that any home that you put them in that will happen but the values might be different.

(Meggie, Nova Scotia)

\section{We are All Human Beings}

Some foster parents did not there were any differences between children from racialized groups and children from non-racialized groups. Foster parents commonly viewed children as human beings, despite their racial or cultural background. The responses, I heard from foster parents, which reflected these views were:

There is not much difference between white and children of color. They mostly put Black children with White families.

(Cindy, Nova Scotia)

I mean a kid, is a kid, is a kid does not matter what they look like.

(Helen, British Columbia)

I guess it is perceiving and having an outlook that we are all homosapians and so we are all connected. Because we bring different ethnic and cultural backgrounds that kind of adds flavour to who we are as individuals. Being respectful of other individuals' views and honouring them and kind of celebrating them is an important thing to do. We do not promote that we are any different... if that 
makes sense. I do not know if that is my own sense of barrier in that I am not doing that. But it is just what feels right.

(Cheryl, Nova Scotia)

I do not care what color you are or the children are...We are all humans.

(Nana, British Columbia)

\section{Experiences of Discrimination}

Foster parents described experiences of discrimination that impacted the services children received. One foster parent realized, during the interview, that some children in her care had been previously discriminated against, by a professional in the community. It was clear she had not thought about the incident as being discriminatory, at the time it occurred, but recognized it as discrimination during our discussion. During the interview, upon realizing what she and the children experienced was discrimination, she stated:

I never thought about it but it is discrimination. Yeah...now I am really ticked off. I just went whatever...you know. I just went to another dentist who had open arms.

(Nana, British Columbia)

A foster parent highlighted the challenges of living 'off reserve' and how this limited her awareness of culturally relevant activities. She described this as a discriminatory practice that impacted her ability to promote the cultural development of children in her care. She told me:

But again, because we are off reserve they do not send us any information. So unless I hear of it from someone else or I happen to go into the band office and 
maybe find out something then we miss out on all kinds of things. If we were on reserve they would drive it to us, they would give us mail but they will not put a stamp on it and mail it to us now. So there is another discrimination issue that I have that she is not getting the information to enrich her life.

(Suzy, British Columbia)

\section{Value of Establishing and Maintaining Relationships}

Foster parents explained the value of establishing and maintaining relationships with children's family members or people from children's backgrounds. They seemed to value these connections more than the child protection agencies and made greater efforts to establish these relationships. Some of the responses I heard were:

I really do not care what the agencies do. My focus is on the children so if the plan is that the child is to be returned to the parent, I get the parent involved as soon as possible. I really do not care what the social workers or the agency say if the plan of care is to be returned to mom and dad, then mom and dad need to be involved in his life. If he is not going home to mom and dad and there is an aunt or uncle then we get them involved as quickly as possible.

(Helen, British Columbia)

Many of our foster parents are very closed and have set ideas. One of the problems I have is that they see their role as being a parent as opposed to being an interim parent. Their role as being, for lack of a better word, saving the children. Their way or their beliefs are the only ones that count and unfortunately many times they discount the culture and beliefs of the children. What we need to 
continue to emphasize is that as foster parents, we support the primary goal and that is to return to family. We encourage family ties.

(Nez Bleu, Nova Scotia)

The grandparents and the aunties and whoever I can get a hold of is who this child gets to see. I totally facilitate and encourage that they know their grandparents and their family but I can only do so much, so my hands are tied when it comes to the rest of her siblings.

(Suzy, British Columbia)

At the same time, they thought that relationships may not develop if foster parents did not seek out and maintain these relationships. They explained the value of maintaining relationships in order to create opportunities for children in the future. Ultimately, they described providing children with resources that would be available to them when and if children chose to establish relationships with their families of origin.

One foster parent told me:

Perhaps I am failing at that where we are not really pushing relationships. We are recognizing the importance of the culture but we are not engulfed in it enough that she would be establishing relationships. We have an open relationship with the family. We have that so when she is an age where she can manage that and choose for herself that we would be able to reconnect, when she can digest all of that. But no, we have not been in a position where we are promoting relationships with the local first nations. It is more of participating in functions but that is kind of the extent of it.

(Cheryl, Nova Scotia) 


\section{Using Racialized Identities to Negotiate Household Rules}

Other fosters parent shared stories about children using their racialized identities to negotiate or be excused from household rules. One foster parent gave the example of children trying to discourage her from contacting their friend's parents, if they wanted to sleep over at their friends' house. She told me:

They moved to our home and we tried to maintain some of the friendships from the old community. Sometimes we would say things like, if you want to sleep over at the house then I need to talk to the mom or dad or the parents. We would have to make these arrangements and again it is like they would not do it. They would say this is a Black community, this is a black parent they do not do that kind of talk to the parent stuff. So some of these relationships did not carry on very far and I do not know how much of it really was a cultural difference between our parenting style and these mysterious parents that would not comply. Or how much of it were kids trying to get one over on us and there were no parents to talk to at all. That issue came up a few times but only in the first year. It disappeared pretty quick. If we had fostered white kids we probably would not have been reminded so often of race and our family. That is just part of that reality that we would not have ever experienced if we were raising a different group of kids. It has affected us in a sense that as family we are reminded that race is part of this equation, a part of this experience, a part of this thing. 
Another foster parent talked about children using their racialized identity to excuse their behaviour or excuse them from certain household rules. He explained children would:

Make assertions like Black parents do not send thank you cards. Black parents do not go to parent-teacher night. Black people will not care where I am or how late I am out. So when we would attempt to do stuff early on in the relationship that they did not want us to do, or we tried to make them do something that they did not want to do, they would sort of play this race card.

(Joe, Nova Scotia)

\section{Strained Familial Relationships}

They also shared stories about strained familial relationships that occurred as a result of having children from racialized groups in their care. Some foster parents were disappointed by the reactions of their own extended family members. A foster parent told me his mother was the only person who he found challenging within his family. He said:

My mother...within our own family my mother. Oh dear...my dear mother, I love her but she carries a lot of baggage. You would wonder sometimes if I was adopted. That is our biggest challenge and it is within the family and it is only mom. The rest of the family has all been very accepting even my family over in England.

(Nez Bleu, Nova Scotia)

One foster parent raised the issue of feeling forced to retreat from familial relationships that may not have welcomed the children. He stated: 
Our social kinship network had shrunk and particularly in terms of my extended family and we had stopped sort of pulled back from relationships with my extended family where the kids might not have been really really welcomed. So we did not experience that lack of welcomeness because we withdrew before the kids came.

\author{
(Joe, Nova Scotia)
}

\title{
Foster Homes Engaging in Cultural Development
}

'Foster homes engaging in cultural development' was another important theme that arose during axial coding. Regardless of how foster parents viewed children in their care or the subsequent importance they placed on culture, every foster parent promoted cultural development. Foster parents simultaneously incorporated culture into their homes and subconsciously promoted cultural development without realizing it. Foster parents told me:

I do things and I forget that I do them because they become a part of my life.

(Nana, British Columbia)

We just sort of build it in the everyday. We try and seek out...especially if we have a child of a different culture. We try to seek out appropriate events for them to participate in with us.

(Antoinette, Nova Scotia)

Each foster parent, and their own families, participated in holiday celebrations from different cultures as well as cultural events such as powwows, smudges or culturally relevant activities. A foster parent told me: 
One of the things that we do is we celebrate every holiday... it is fun. We also do a lot of cultural inclusion. If there is something that will be culturally relevant to a child in our care then we partake in that. Certainly we have read a lot; we have talked to individuals of color and asked a lot of questions. We have asked a lot of questions so that we know...so that we do not go and blow it for the kids. We find we are able to get involved in much more cultural activities outside of the valley as opposed to in the valley.

(Nez Bleu, Nova Scotia)

Another foster parent said:

We look up Indonesia on the map and we find out any celebrations they might do in Indonesia, and food. We will have an Indonesian night and if I had a child from Mexico we would celebrate their traditions. We celebrate everything and if we do not have anything to celebrate...we celebrate Tuesday. We go to training with the Ktunaxa (pronounced 'k-too-nah-ha') Nation and find out as much as I can about different cultures so that we can incorporate it and use it in. A lot of it is determined by the kids that I have in care. We try to make it as normal...whatever that is, as possible. It depends a great deal on the foster parent what they are willing to do.

(Helen, British Columbia)

One more foster parent said:

I want for my daughter to be in her culture to see the native people...the elders... to mingle with them, to go talk to them because she only has her grandma and grandpa.

(Suzy, British Columbia) 
Foster parents subsequently incorporated children's culture into their homes through meal preparation, spiritual practices, artwork and traditional concepts from children's culture of origins. One foster parent told me:

The assistant chief came out and smudged the house and blessed it to get rid of monsters [a child] thought were under her bed.

(Suzy, British Columbia)

They also told me they read books on culture, watched movies and identified as well as discussed the leaders from children's cultures. They visited libraries, local communities where children were from, festivals as well as museums. They indicated they sought out and participated in these activities on their own. They also indicated they usually found out about culturally relevant activities through sources other than child protection agencies.

Furthermore, these activities were largely determined by the cultural needs of the children in their homes as well as the availability of resources in the community they participated in. Participants said:

Like for example for our first little Jewish guy, we went and saw a Rabi and spent quite a bit of time with him.

(Nez Bleu, Nova Scotia)

We try and seek out...especially if we have a child of a different culture we try to seek out appropriate events for them to participate in with us.

(Antoinette, Nova Scotia)

Most foster parents described being comfortable seeking out culturally relevant resources in their communities. However, some foster parents questioned the decisions 
they made, on behalf of children, regarding culturally relevant resources. One participant described her discomfort about being the only one making these decisions about children's culture of origins for them. She said:

I was also a bit cautious about assigning certain identities to the kids that might not be really appropriate....the kids are Black, therefore they are Baptist, therefore they belong in this church or therefore they... you know...this is the church tradition that they should have. From what the kids recollect, church was not a big part of the family experience when they were in Africa. It only really became part of their family after coming to Halifax. It may have been more of a vehicle to access other Sudanese and Ethiopian immigrants. It might have been less about religion and more about cultural identity, community kinship kind of thing. Certainly I am, in terms of my own comfort, but the comfort gets problematic because of the kids. Different circumstances with the kids and I would be more comfortable. I might have pushed harder with the Baptist church but I think what inhibited me there was an awareness that, in a way, I was constructing an identity in that sense. This might be a good support... but based on what? There is something a little uncomfortable about dictating a culture onto a kid. About me being the power that decides what the culture is. Ideally we would want to just open the doors, and go eat at that house, and hang around with those kids, and go to that dance or that movie and let it happen. But because that did not work out, then you start picking and choosing. Then you feel arbitrary and a little racist and you question the validity of it. Then I start to not push so hard.

(Meggie, Nova Scotia) 


\section{Increasing Cultural Awareness in Foster Homes}

Increasing cultural awareness in foster homes was a critical theme among the interviews. Every foster parent described the impact of having children and youth from racialized groups, in their homes, as a rewarding experience that subsequently benefited their own families. Foster parents told me:

Oh my goodness. It has made us more aware actually. It has made us an awful lot more aware of other cultures, other nationalities, other religions. It has been an eye opener for us.

(Nez Bleu. Nova Scotia)

It has all been positive. My kids are very accepting of the kids that I bring now when I go visit them and my grandkids are way more sensitive I would guess to other children who may be in care.

(Helen, British Columbia)

I do not think that there has been any impact on us other than continuing to be aware.

(Cheryl, Nova Scotia)

Moreover, they spoke about the increased overall awareness they, as well as their children, had as a result of having children from racialized groups in their homes. This awareness was manifested in a variety of ways. Some foster parents indicated their own children became foster parents. One foster parent told me:

It has just become part of our family. It is a good learning experience, it is interesting. My family has been fantastic and actually two of the girls foster also because of me. They are all First Nation children too. It has affected our family 
by more members of the family becoming foster parents of First Nation children. It's really nice.

(Nana, British Columbia)

Some foster parents also became extremely vigilant about the products they purchased. For example, foster parents ensured they acquired goods that were produced under fair terms of trade for farmers, manufactures and workers in the developing world. They described having discussions with children and with their own families, about the importance of purchasing 'fair trade' goods such as: sugar, coffee and chocolate. These discussions seemed to resonate with children from racialized groups. According to one foster parent I spoke with:

We have always been really careful about the coffee that we buy, the sugar that we buy and the chocolate. We talk about that with the kids and recognize that this is fair trade chocolate. We have that awareness and now they have that awareness (Meggie, Nova Scotia)

For some foster parents, they were intrigued by the emphasis some Black children placed on their hair. They could not believe how time consuming and highly valued hair was to some Black children. They told stories about spending the entire day at a hair salon getting children's hair braided. When it came time to have their hair braided again they described spending an entire day taking the braids out and this, sometimes, involved the entire family. One foster parent told me:

Hair has been much more of a focus... or has been a lot of focus of our family life. 6 hours at the hair salon, I could not believe it. 
Another foster parent told me:

I never in my life imagined how much time one could spend on hair care and hair product and hair pain. I can almost bring myself to tears right now just thinking about hair which is not something that I had ever experienced. It is so big. It is incredible. It is almost everything and I have said in a joking way, I never imagined in my life that I would call a kid in absent from school for a bad hair day. But it was a legitimate call...that kid could not go to school that day. Like there was no way she could face the world on this particular day, with this particular experience and the particular hair issue. It would have been cruel to send her out there but that was something that white women do not... you know...

like put on a hat. It does not shake you to your core. That was really enlightening and that was an effect of having the kids.

(Meggie, Nova Scotia)

\section{Limitations and Challenges Foster Parents Faced}

The limitations and challenges foster parents faced coalesced around the nature of child protection and the circumstances revolving around the removal of children from their homes. Foster parents identified the available resources or lack thereof, the impact of child protection policies, poor communication between foster parents and child protection agency workers as well the attitudes of child protection agency workers as factors that created limitations and challenges for them to promote cultural development.

\section{Limitations of Child Protection}

Foster parents indicated that opportunities to promote cultural development were limited due to the circumstances revolving around the apprehension of children. Some 
foster parents felt the agencies they worked alongside withheld information about the children in order to have the children placed. A foster parent said:

They do not tell the truth when they drop these kids off either because they know no one will take them.

(Suzy, British Columbia)

They thought the logistics of trying to promote cultural development and cultural identity was contained to their homes because of children's circumstances. One foster parent told me:

We consume it in the home, consume in the books and the movies and the university thing but we do not get to consume in the restaurants or in the houses or on the street. It always has to be in a safe environment that is not likely to share space with people from the actual community we are trying to engage with...it is all very contained. We do not actually get to participate physically in the cultural events. So we talk openly and honestly about having a strong black consciousness and then how do we go about doing that? The reading and the talking and the thinking and the debates...that is largely how we do it.

(Meggie, Nova Scotia)

Some foster parents also identified challenges because they did not have or were not provided with pertinent information about children's backgrounds from children protection agency workers. They described challenges such as: not having information about where children were born or who the biological parents of children were. They felt this information would assist them while caring for children. They said: 
Their parents are from Ethiopia, the children were born in Sudan. Do not know where their passports are. Do not know where their birth certificates are. Not really sure where this all traces back so that has affected how we approach it.

(Meggie, Nova Scotia)

Very few people know who the fathers of the children are, so they do not know...lots of incest in the last generation.

\section{Limitations of Community Resources}

(Suzy, British Columbia)

Another important theme that emerged was that foster parents were limited by community resources. Foster parents indicated they acquired and accessed culturally relevant resources by their own means and was based on availability. For example, the activities they participated in were limited, at times, by geographic location or lack of resources. One foster parent told me:

There is not too much other things in this small area for Blacks and Natives.

(Cindy, Nova Scotia)

When I asked about culturally relevant resources available to them, one foster parent told me:

In this area I do not think so. It depends a great deal on the foster parent, what they are willing to do. Down in Vancouver you have got a sizeable say Chinese population and East Indian. So they do have the Dhwali. If I was down there and I had a child of East Indian descent we could find out about it and participate and see what they are doing and check it all out. [Where I live] is basically a white town.

(Helen, British Columbia) 
Foster parents were also limited when the available resources did not respond to attempts to establish contact with them, on behalf of children. One foster parent:

I reached out on a couple of occasions. I called the church, I called the minister and my phone calls were never returned. So we never actually attended that church. So sometimes we did things to increase our knowledge and understanding of particular cultures in our community and it did not lead anywhere...the church kind of closed the door to the kids after the apprehension and when the court case was supposed to happen. It was not possible to take the kids to the church and the kids could not go to the church so we just maintained this sort of a...it was actually quite a secretive relationship that was supposed to be hidden from the community. But at least they had that one bond.

(Meggie, Nova Scotia)

After unsuccessful attempts to establish contact with available resources another foster parent thought:

These resources seem to peter away to a degree, either the kids did not want to maintain the connection or the activity or maybe we did not have the stamina because it takes a lot of effort.

(Joe, Nova Scotia)

\section{Limitations of Child Protection Confidentiality Policies}

Foster parents highlighted the limitations of the child protection agencies confidentiality policies that impacted their opportunities to promote cultural development. Most foster parents willingly sought out and participated in cultural activities that promoted the cultural development of children and youth in their care. 
However, there were occasionally limits placed on them due to the protective and confidential nature of child protection agency policies. One foster parent explained:

It never occurred to us, before the kids came, the types of limitations that would exist. Not until the circumstances were in our home. Because when we were filling out the forms and talking in theory hypothetically about what we were going to do. We are going to the black cultural centre, Ethiopia day and eat at this restaurant. Then the kids arrive and we cannot do any of it that. It was an interesting lesson that it does not work in practice as nicely as it works in theory. But that is what you kind of become aware of when your resources are limited and the way that our resources are limited and for really important reasons.

(Meggie, Nova Scotia)

Foster parents also felt the child protection agency policies regarding confidentiality hindered the work they did. They felt these policies about confidentiality did not apply to some cultures and limited the information they were provided about children. One foster parent told me:

Confidentiality can get in the way sometimes. Personally, I find the whole confidentiality thing is done to the point where it hinders the work that is being done. I will give you an example, within our own agencies that confidentiality goes too far. You can have three or four different people working with the same family and being unaware of the other parts of the story because of confidentiality. We do have a lot of problems with getting information about the kids, especially with some of the workers. We are not allowed to share 
information. Culturally it is inappropriate not to share that information and that is something that has been lost to the powers at be here.

(Nez Bleu, Nova Scotia)

It became evident that policies regarding of confidentiality, within child protection agencies impeded foster parents ability to access culturally relevant resources. Some foster parents spoke about having no choice but to integrate culture into their lives and children's lives by exploring it within the protective walls of their home. One foster parent told me:

These other issues about protection and confidentiality and privacy and safety and that kind of stuff that actually built walls that inhibited the cultural experience.

That is a big piece to overcome.

(Meggie, Nova Scotia)

Foster parents faced challenges, related to the circumstances surrounding the apprehension of children that impacted their ability to access culturally relevant resources. One foster parent explained the fears children had about information being relayed to their biological father, if they were recognized in their community of origin. She never thought the ideas she had around promoting culture and participating in community events would be limited by virtue of children's circumstances. She found it challenging that she could not practically implement her ideas. She said:

My guess is that the types of reasons, the types of problems that we encountered in terms of confidentiality and protection, is probably a lot more common than just this home. But it is not something that was ever raised in the training. Confidentiality was raised in the training but it was never married to the idea that 
it would limit your cultural resources or activities. They tell us we have to protect their story and next page, cultural identity list twelve places where you can go get cultural identity. So we dutifully list the twelve places, and no one says...well guess what? Nine of them are going to be unavailable because they are going to be afraid that information will seep back to the birth dad...that is the reality. You often wonder about the role that confidentiality plays in terms of protecting the kids from support, protecting them from resources, protecting the kids from understanding and protecting the kids from a deeper sense of self. I think in order to get a deeper sense of self, in this sense, we need to be able to kind of open the gates a bit more in the information and talk really openly and freely to a lot more people and not just in these modules seven or whatever the hell it is and sensitivity training.

\section{Challenges Regarding Communication}

Some foster parents faced challenges when communicating with children about cultural issues and about cultural identity because of language barriers. One foster parent told me:

Language has been a huge challenge in this particular placement because they did not speak English. But they did not speak English because they were not born in Canada not because they are Black. Had we had kids from Turkey or Germany it would have been the same problem....For example, the kids will say I am not Black I am Brown and my sense is it is sort of like a developmental and language piece. They are being quite literal about the color of their skin and yet Black and Brown in a cultural sense mean different cultural identities and I have tried to 
explain, but that kind of stuff is a tricky thing for a white woman to explain to a Black child.

(Meggie, Nova Scotia)

Foster parents also faced additional challenges that arose through interactions with the child protection agency workers. They thought that the lack of communication between child protection worker and foster parents presented challenges. Foster parents said:

There are ups and downs but the downs always involve workers and you know you do not always see eye to eye with workers.

(Nana, British Columbia)

Communication is nonexistent. The transition is nonexistent which is absolutely criminal, as far as I am concerned. Foster parents are kept in the dark about what other foster parents are getting, doing, so there is no help for foster parents between themselves at all, it is very frustrating.

(Suzy, British Columbia)

Another challenge identified as potentially impacting children and youth from racialized groups was the attitude some foster parents had about children's biological parents and vice versa. One foster parent told me:

The perception that the natural parent is the enemy or the perception on the part of the natural parent is that the foster parent is the enemy.

(Nez Bleu, Nova Scotia)

\section{Challenges Regarding Child Protection Workers' Attitudes}

A few foster parents found the attitudes of the staff, at some child protection agencies, challenging. For example, one attitude was that White people should not be parenting 
Black children and Mi'kmaq children. Foster parents indicated these rigid views impacted the ways in which they carried out their roles in children lives. One foster parent described these beliefs as a hindrance to discussions between child protection agency workers and foster parents. She said:

What happens when people become too aggressive or too entrenched in a position about stuff like this it makes it hard for people to talk openly and honestly about stuff and that hurts the kids.

(Meggie, Nova Scotia)

Another foster parent also described the challenges apparent in the divergent views between workers, agency policies and subsequent geographical regions. He said:

Policy wise they are supposed to support involvement of natural parents but it varies by worker. Some workers are very hesitant about that. Some offices are very hesitant about that. One of the offices nearby cannot understand why you would ever want to put foster parents and natural parents together. It is just so contrary to what they [child protection workers] have believed for so many years as an agency. The best thing you can do is get on side with the natural family and become a resource for that family which is very very important.

(Nez Bleu, Nova Scotia)

One foster parent told me about her frustrations with the child protection agency's view on culturally appropriate versus culturally competent foster parents. She explained that the child protection agency deemed her home as culturally inappropriate but culturally competent. She felt they made this decision based on her and her husband being white. She was frustrated by the way the child protection agency narrowly defined 
cultural appropriateness, because she felt it encompassed more than just race or skin colour. She believed determinations about cultural appropriateness should consider dynamics such as: language, religion and immigration status. She also felt this narrow view made her feel as if she had to defend herself because her home was viewed as culturally inappropriate. She explained:

We can be considered culturally competent but we cannot be considered culturally appropriate... But I still have this problem that it would be considered culturally appropriate to put them into a Black Nova Scotian home that does not have the language or the religion or the national or the immigration experience. Like all of those things do not match. That is challenging for me because it frustrates me a little bit that they are defining appropriateness so narrowly, according to basically...skin colour... Not considering language, religion, ethnicity or immigration. These are all identity pieces...cultural pieces for these kids that other families might not recognize. So they might be culturally appropriate but not competent. So that piece has been a bit of a challenge...it is been a kind of a pet peeve.

(Meggie, Nova Scotia)

Fortunately, there were some foster parents who did not find anything challenging about being involved in transcultural foster care placements. A foster parent said: Up here I have social workers dropping in to visit me maybe once or twice a month. Not necessarily to see the kids but to see me and have tea and find out how things are going and that is good.

(Helen, British Columbia) 


\section{Advice for Foster Parents and Child Protection Agencies}

Foster parents were extremely clear about what they needed in order to address some of the challenges they experienced. In order to address these challenges, foster parents offered advice and recommendations for existing as well as future foster parents, child protection agencies and other professionals involved in child protection.

\section{Advice for Foster Parents}

They thought that working with children's families and embracing culture were beneficial to children and youth from racialized groups in their care. According to one foster parent, it would be helpful if existing and future foster parents liaised with children's biological families so they can:

Care for them in a manner that they are accustomed to.

(Antoinette, Nova Scotia)

Another foster parent suggested the following:

Leave preconceived ideas behind and look at working with the child or any child for that matter as an open book. And if you can work with the natural families you certainly learn a heck of a lot more in terms of working with children of color. If you want to look at working with children of color, the best thing you can do is get on side with the natural family. Then you can work together to make sure that what they are doing to preserve their identity is in the best interest of the child from our point of view and the parents point of view.

(Nez Bleu, Nova Scotia)

Foster parents expressed the value of seeking out resources and incorporating culture into their homes and suggested future foster parents embrace culture. They said: 
Try to deal with the needs of the child as much as possible to let them continue with their culture. Try to keep their culture in their lives as much as possible.

(Cindy, Nova Scotia)

Relax and enjoy the kids. Find out as much as you can because everything you learn broadens your horizons.

(Helen, British Columbia)

Another foster parent said:

Do some research on the culture; get to know the beauties of the culture. Like what are positive aspects of any culture and what they bring so that you can celebrate those and engage yourself as much as possible in that culture. I do not think everyone would be as open to putting themselves in a minority situation. To me it is kind of a unique way to have an understanding of how people feel. So if you can place yourself in that minority situation by engaging in the cultural. Then that is going to give you an awakening about how you feel about things. That is how you are going to learn about the culture and what is neat from my experience is that that is welcomed. When they have an understanding that you are only interested in their culture they feel quite honoured in sharing that. It has been our experience that they welcome you.

(Cheryl, Nova Scotia)

They also suggested future foster parents establish relationships with other foster parents involved in transcultural foster care placements. One foster parent provided the following advice to future foster parents: 
Find someone in the foster community with similar experience. Encourage them to do everything we have done in terms of reaching out to community supports. Plus all that we would have done if the circumstances were different.

(Meggie, Nova Scotia)

At the same time, Meggie cautioned future foster parents about the attempts they made to promote the cultural development of children and youth from racialized groups. She highlighted the importance of providing the opportunities for children to make decisions about culture when and if they wanted to. She offered the following:

Some of my advice to other foster parents while you are being this arbitrator of culture. I would caution you maybe a little bit, to be a bit mindful of the fact that we cannot. It is not so easy to dictate what this culture should look like. We cannot just go to the library and take out these books on Ethiopia and decide that this is what the kids should be like. So the trick is to open as many doors, build as many networks, build as many relationships to expose and connect the kids to as many people from that experience as we can. Let them be the arbiters of the culture and let that cooking smell, that hairdo and the clothing and that music organically happen.

(Meggie, Nova Scotia)

\section{Advice for Child Protection Agencies}

Foster parents thought child protection agencies should have a greater role in connecting them to culturally relevant resources. One foster parent offered the following advice: 
So perhaps what needs to be improved is the role of [child protection agencies] connecting us with those other resources that already exist. They do not have to reinvent the wheel; just make an appointment for us. Even at the very lowest standard, hand us a business card. But I would argue that it maybe even more appropriate to say let me set up an appointment for you to talk with them.

(Meggie, Nova Scotia)

Some foster parents suggested having a space, provided by child protection agencies, for them to sit down with the professionals who are the guardians of children to discuss issues related to culture and identity. For example, they would like to be able to ask social workers or other professional's questions regarding race, culture and identity. One foster parent would like to ask professionals:

What do you think about this Brown/Black thing and how should we approach that? What conversations should we be having and the training opportunities where that might theoretically happen?

(Meggie, Nova Scotia)

Moreover, Meggie thought it would be helpful for child protection agencies to provide opportunities for foster parents to engage in discussions about race, culture and identity. She said:

If we went to a supervisor right now and said we have foster parents out here dealing with this really difficult intellectual cultural thing. Maybe you ought to provide an opportunity for them to explore or discuss, unpack and deconstruct. They will say they can do that at the sensitivity course or they can do that in the PRIDE module about cultural identity. Well no... they cannot because everyone 
else in the room is being explained why we cannot say Indian. And that is probably something that community services cannot even maybe begin to address because of resources. Or maybe they can say to the bright and educated social workers who have master degrees and all kinds of stuff. Maybe you need to carve out some time in your schedule to sit down and have this chat. Not to dictate how the parent might do it, but to explore and discuss and to give them an opportunity. And if you do not want that, maybe you can pay some money to somebody and make an appointment with them. Open the door to that discussion because we have been having this discussion for three years.

Meggie also thought it would be beneficial to identify professionals in the community that foster parents could speak with openly without confidentiality policies limiting these conversations. She told me:

Could we identify some people some trained professionals? So we can throw out the confidentiality stuff because all this stuff, as you know, is very fluid. It all intermixes so in order to talk about the race, culture identity piece. We also recognize the attachment piece, the abuse piece, the developmentally delayed piece, the do not understand the English language piece. So we have got to bring all that onto the table in order to talk about how I can best encourage these kids to be culturally confident, culturally aware. Have their identity and be proud of it. I get mixed messages from [child protection agencies] about who I am allowed to put all that on the table with.

(Meggie, Nova Scotia) 
They also indicated that training was an important piece that was sometimes missing, depending on the community they lived in. One foster parent was frustrated by the lack of training provided to her in her community. She believed child protection agencies were responsible for this lack of training because of postponed training dates and lack of follow through by workers. She also believed that ongoing specialized training would encourage foster parents and educate them to assert themselves to advocate for the rights of children in their care. She suggested the following:

Genealogy training to let them know who their brothers and sisters are because they are so related on the reserve. They do not know if they are making out with their cousin, because they do not know who they are related to....Self-esteem, enriching, assertiveness training so that they have the power within them to be able to assert themselves. Not be passive or aggressive with their children or with the social workers or other agencies that they have to deal with especially teachers, they are hard... Racism training because it is huge on our reserve. We have half that hate whites and half that appreciate them so training on racism.

(Suzy, British Columbia)

\section{Fostering Cultural Development}

Selective coding was the final stage of data analysis. The overall core theme that integrated the categories and subcategories was that foster parents were 'fostering cultural development'. Selective coding integrated 'fostering cultural development' with the other categories validating the relationships and completed the data analysis process (Creswell, 2007). This term reflects the individual efforts foster parents made to promote the cultural development of children and youth from racialized groups. 
The majority of participants felt their personal experience, previous education and work experience had a greater impact on their awareness of culture, than the available foster parent training did. Foster parents in this study were committed to seeking out opportunities, activities, relationships and resources to integrate culture into the lives of children they cared for.

Unfortunately, foster parents did not always have the support of child protection agency policies or workers when making decisions about culture. They felt policies regarding confidentiality interfered with their opportunities to promote the cultural development of children and youth from racialized groups. They also felt the attitudes of some child protection agency workers impacted their ability to communicate openly and honestly regarding children in their care.

Although foster parents were making concerted efforts to make decisions, in the best interest of children, they thought improvements needed to be made within child protection agencies. For example, they felt specialized training and support, improved communication with child protection workers, as well as less stringent policies regarding confidentiality would assist them in their role.

This chapter presented the themes that emerged from this study, supported by the voices of foster parents who participated in this study. The following discussion chapter connects these findings to some of the existing literature while highlighting the similarities and differences between the experiences of foster parents, in this study, and those in the literature. It also includes the implications for child welfare policy as well as the implications for social work practice. 


\section{Chapter 5 Discussion}

Throughout my interviews with foster parents, involved in transcultural foster care placements, it became quite apparent that foster parents were promoting the cultural development of children and youth from racialized groups in foster care. Most foster parents, in this study, had to seek out resources, activities and culturally relevant information on their own. Through this research study, I learned that foster parents made decisions related to the cultural development of children in isolation, with little or no input from child protection agency workers. Subsequently, foster parents were responsible for establishing relationships for children and youth, with culturally relevant people or supports available to them in their respective communities.

Despite provincial legislation, in British Columbia and Nova Scotia, that speaks to the preservation of the religious, cultural and linguistic heritage of children in foster care when practical, as well as ABSW's position statement against the placement of Black children in non-Black foster homes, children from racialized groups are placed with foster parents from non-racialized groups. While anti-oppressive theory recognizes "that injustice and inequality exist and are maintained through political and economic arrangements, it also points out that power is dispersed widely throughout society and culture" (Strega, 2007 p. 73). Working from an anti-oppressive perspective incorporates an analysis of power and structural inequalities on people's lives with a focus on social action and social change (Cain, 2006).

Within the context of child welfare, anti-oppressive theory suggests power "is not just enacted in large spheres that feel like they are beyond our control" but power is also acted out in individual, social, political, cultural, and economic relationships (Strega, 2007 p. 
74). Accordingly, perceptions of child protection are often linked to concerns about power dynamics. Social workers have the delegated authority to remove children from homes based on particular circumstances or when protection issues arise. Children, who are inevitably powerless, are removed from their homes and placed in foster homes with foster parents who provide care for them. Within foster care placements, power is delegated to foster parents, by social workers, based on the contractual agreement in place.

Subsequently, foster parents exercised their power by determining or meeting the needs of the children in their care. Specific to children and youth from racialized groups, foster parents were in a position of power to determine or dictate the cultural needs of children in their care. At the same time, foster parents were in a powerless position because they received minimal support from child protection agencies. Since children and youth from racialized groups are likely to be placed with foster parents from nonracialized groups, the findings of this study suggest foster parent's cultural receptivity be assessed prior to and throughout the foster care placement.

Cultural receptivity involves a foster parent's openness to encourage children's relationships with people who share their cultures, find resources where children can go to get their cultural needs met, learn about parenting strategies from the children's culture, and learn from other people who have parented children from racialized groups (Coakley et al. 2006). Therefore, the cultural development and identity formation of children and youth from racialized groups can be supported throughout transcultural foster care placements, if foster parents seek out and have access to culturally relevant people and resources. 
In this study, foster parents facilitated relationships with children's biological families or other members from children's birth cultures. Foster parents also identified the need to have guidance about the activities available to them, selecting appropriate communities, organizations as well as individuals and respectfully making connections to those potentially helpful resources. Therefore, the experiences of foster parents, in this study, are consistent with the findings in existing research (Brown et al., 2009) because foster parents indicated they were provided with minimal guidance, support as well as resources from social workers. For example, foster parents wanted more than one worker or position within the child protection agency to be aware of and responsive to children experiencing issues related to culture (Brown et al., 2009).

While foster parents incorporated culture into children's lives and subsequently into their own homes, foster parents faced challenges. These challenges were as a result of child protection agency policies and, in some cases, members of their own extended families. Due to the confidential and protective nature of foster care, the activities foster parents could participate in, with the children, were significantly limited. Foster parents, in this study, saw benefits to identifying professionals in the community to facilitate safe discussions regarding culturally relevant topics. Consistent with the findings in a Canadian study conducted by Brown et al. (2009), foster parents felt the perspectives of birth families, other foster parents, professionals in the system as well as government representatives are required for change to occur.

By the same token, researchers (Brown et al., 2009; Vonk, 2001) found that foster parents wanted culturally sensitive resources and a significant barrier to foster parents participating in activities and their confidence to foster transculturally was the perception 
they had about how accessible these culturally sensitive resources were to them. Contrary to previous research (Brown et al., 2009; Vonk, 2001), foster parents in this study felt comfortable seeking out and accessing culturally relevant resources. However, they felt limited by policies regarding confidentiality and available culturally relevant resources.

Researchers (Brown et al., 2009) also found that foster parents had a desire to obtain knowledge about the children's communities, and viewed children in their homes as the teachers of culture, which is consistent with the views expressed by foster parents in this study. Consistent with these findings, in this study, the activities the foster parents participated in were largely determined by children's cultural and/or racialized backgrounds. Foster parents promoted culture to the extent they felt comfortable seeking out resources, the awareness they had about the cultural needs of the children, the importance they placed on culture, the impact they felt culture had on a child's development, and the accessibility as well as availability of culturally specific resources.

Research (de Haymes \& Simon, 2003, Vonk 2001) also found that foster parent's confidence and practice in dealing with the perceptions of others about their motives to foster, the response of their own extended family members to the child, and combating racism in their community could be effectively enhanced through participation in training. However, training for foster parents was not consistently provided depending on the geographic location and the availability of staff and/or funding to provide this training. Consequently, foster parents in remote areas had fewer resources available to them and most of these foster parents indicated they had to travel into the city in order to participate in culturally relevant activities. 
The reasons foster parents did not attend or receive training were similar to those documented in the literature. For example, ongoing training for foster parents is often hampered by many factors such as lack of resources, scheduling problems, transportation issues, access to respite care in order to attend training, and a lack of priority given to training by the foster care system (Twigg, 2009). Therefore, this study also supports the finding that only a small percentage of foster parents actually receive post licensure training on working with children of a different race than that of the foster parents (Rhodes, Orme \& Buehler, 2001).

Despite these challenges foster parents found the experience, of fostering transculturally, rewarding. Most foster parents felt their biological children became more aware of issues related to race and culture and in some particular cases; their biological children eventually became foster parents themselves. In general, the personal or work experiences of foster parents far outweighed the training they received through the child protection agencies they worked with. Moreover, it was evident the foster parents, in this study, were culturally receptive despite receiving, participating in or the effectiveness of the training they were offered through child protection agencies.

Participants' responses were consistent with the framework of cultural receptivity which involves foster parents willingness to seek training, support and services to increase their transcultural foster parenting abilities (Coakely et al., 2006). Foster parents, in this study, were open to participating in activities that supported the cultural development of children, in foster care, from racialized groups. Specifically, foster parents were extremely open to encouraging the children's relationships with people who share their cultures, finding resources where these children can go to get their cultural 
needs met, learning about parenting strategies from the children's cultures, and learning from other people who have parented children from racialized groups (Coakley et al., 2006).

Research has documented the importance of cultural receptivity in fostering and has shown that cultural receptivity can be enhanced through training (Baden \& Steward, 2000; Coakley \& Buehler, 2008; Coakley \& Orme, 2006; Cross et al., 1989; de Haymes \& Simon, 2003; Massatti et al., 2004; Vonk, 2001; Vonk \& Angaran, 2001). However, the personal or work experiences of foster parents, I spoke with, far outweighed the education and training they received through the child protection agencies they worked with. As expected, their stories uncovered the need for changes to support foster parents in promoting the cultural development of children and youth from racialized groups.

Foster parents provided invaluable information to help guide future policies for foster parent recruitment and retention, training, future child protection casework practice and future research in this area. Foster parents also made suggestions for child protection agencies, to enhance the opportunities for foster parents to promote the cultural development of children and youth from racialized groups in care. Within child welfare, particularly in the area of child protection, anti-oppressive practice must challenge oppression within larger systems as well as oppressive agency policies and practices. Based on their experiences, as well as my analysis of the emergent themes, the implications for child welfare policy, and the implications for social work practice are outlined below. 


\section{Implications for Child Welfare Policy}

The findings of this study warrant the attention of the child welfare field to better inform policy, social work practice and social service delivery. This study presented information, shared by participants, that serves to determine the needs of foster parents involved in transcultural foster care placements. It also subsequently identified the gaps, in the existing services, that can potentially impact children and youth from racialized groups in foster care.

Participants accepted their roles as caregivers, as well as a non-mandated responsibility to provide opportunities for cultural development to one of society's most vulnerable populations. As demonstrated by the findings, decisions foster parents made regarding cultural development were arbitrary, with little input from child protection agency workers.

As the delegated legal guardians of children in foster care, social workers need to take a more active role in ensuring the cultural development, of children and youth from racialized groups, is not compromised. When social workers are considering placements for children and youth from racialized groups, in foster homes, the basis of their assessments should explore aspects of cultural receptivity.

Moreover, as part of their role, in making determinations regarding culturally appropriate or culturally competent foster homes, they should consider how culturally receptive foster parents are. At the same time, social workers should be responsible for providing adequate resources as well as establishing and facilitating connections to culturally relevant resources. 
In remote communities with limited resources, social workers need to develop culturally relevant resources or provide culturally relevant resources to foster parents and children. For those whose geographic location creates limitations regarding accessibility, social workers, as the legal guardians, should be responsible for taking children and youth to available culturally relevant resources. Furthermore, if there are limits to foster parent's ability to take children to resources outside their communities, social workers should ensure children are provided with transportation to access resources to meet their needs.

In both remote and urban communities, social workers should also be required to provide in-home resources to foster parents and children and youth from racialized groups in their care. By providing in-home resources, limitations posed by confidentiality policies could be mitigated. For example, in-home resources could provide foster parents, as well as children and youth from racialized groups, with the opportunity to engage in culturally relevant activities. Specifically, a professional or an identified member from children's culture of origin can be called upon to provide support, guidance or assistance with daily activities. This arrangement will assist foster parents in gaining access to culturally relevant resources, while minimizing children's fears of being recognized in the community or concerns regarding confidentiality.

Subsequently, policies regarding confidentiality should be adjusted, to minimize the limits placed on foster parent's ability to communicate their needs and concerns regarding children in their care. This would allow foster parents to have discussions and seek advice, if they are in need of support or are faced with a challenging aspect of fostering transculturally. It would also benefit children, in foster care, because foster 
parents can obtain required support to assist them in meeting the needs of children and youth from racialized groups.

Additional policies need to be created to assist foster parents in meeting the needs of children and youth from racialized groups. These policies would ensure children and youth from racialized groups have access to culturally relevant resources. Furthermore, polices should focus on increasing social workers responsibilities for ensuring children and youth are exposed to their culture of origin, either directly or indirectly.

Direct exposure would consist of social workers physically engaging children and youth from racialized groups in culturally relevant activities, communities and practices. To avoid hindering direct exposure, community resources need to be identified and available, for foster parents to access. For example, agreements should be made with community resources to respond, in a timely manner, to foster parent's requests for support or assistance. These resources should also be identified as 'safe places' for foster parents to speak openly and honestly, while seeking assistance as well as establishing relationships for children and youth from racialized groups. Furthermore, social workers should identify 'safe people' such as elders or trained professionals who foster parents, as well as children and youth from racialized groups, can draw upon for support. If it is not practically possible to provide children and youth from racialized groups with direct exposure, social workers should provide children with indirect exposure to culturally relevant resources.

Indirect exposure would include social workers providing educational resources or making efforts to maintain accurate records, medical histories, contact information and other pertinent information about children's biological families. This information should 
be accessible to both foster parents and children in their care, to ensure children are aware of critical information that may impact them in adulthood. For example, these records would be useful if a child in care required a mental health assessment, or if establishing a blood line was required to determine eligibility for available funding or additional resources.

In order to ensure children and youth from racialized groups are either directly or indirectly exposed to culturally relevant resources, it should be a requirement that social workers identify and establish connections for foster parents. As part of initial placement arrangements and ongoing case management, social workers should provide names and contact information for available resources in the community. Ultimately, a policy should be implemented that requires social workers to schedule appointments, or establish contact with culturally relevant resources, for children and youth from racialized groups in foster care.

The findings, of this study, highlight policy implications for the child welfare field that need to be implemented to best serve foster parents, as well as children and youth from racialized groups. Until such policies are created and implemented, foster parents will continue to make to arbitrary decisions regarding culture with little input from social workers, who are the legal guardians of children in care. While policy requires social workers make decisions in the best interest of children, additional efforts need to be made through practice implications, to support the cultural development of children and youth from racialized groups in foster care. 


\section{Implications for Social Work Practice}

Social workers, working in child protection, are delegated by the Provincial Government to make decisions regarding the safety and well-being of the most vulnerable children in society. In order to protect some children, decisions are made to remove children from their natural families and place them in foster care. The decisions social workers make are guided by legislation, policies and procedures specific to each province.

Provincial legislation suggests the cultural, linguistic, religious needs of the children should be considered when placing children and youth from racialized groups. It was clear, through this research study that this does not always happen and children from racialized groups are placed with foster parents from non-racialized groups. Since the transition into foster care can be a traumatic experience for children, it is reasonable to assume the racialized background of some children can contribute an additional dynamic to this experience.

This study found that once the decision was made to place children and youth from racialized groups in a foster home, foster parents were primarily responsible for integrating culture into children's lives. The results of this study indicate that a consultative process is needed for foster parents to discuss issues related to race and cultural development. Therefore, developing support groups for foster parents involved in transcultural foster placements, providing specialized training, improving communication, facilitating discussions with other professionals or members from other cultures are all ways that social workers can support foster parents. Additionally, social 
workers can create support groups for children and youth from racialized groups involved in transcultural foster care placements.

At the same time, the current policies regarding confidentiality in child protection, hindered foster parents opportunities to promote the cultural development of children and youth from racialized groups. It would be beneficial if social workers identified elders or professionals, in the community, who foster parents could speak with openly and honestly. As part of this process, confidentiality policies need to be adjusted to prevent placing limits on these conversations, while creating a space for these discussions to occur.

This chapter highlighted the similarities and differences between the findings from foster parents in this study and the existing literature. The next chapter presents my conclusions and recommendations for future research in the area of transcultural foster care placements. 


\section{Chapter 6 Conclusion}

\section{Conclusion}

My personal experiences of racism as well as my professional experience, working with individuals involved in the criminal justice system, contributed to the conceptualization of this research study. As a Black Canadian, working with individuals who have either been in the foster care system or have children in the foster care system, I became interested in exploring transcultural foster care placements. Using social constructionism as a framework, I highlighted the perspectives of overlooked and critically positioned foster parents, who have more direct contact with children and youth from racialized groups, than any other child protection stakeholders do.

This study explored foster parent demographics, training, relationships and circumstances associated with cultural receptivity as well as their willingness to incorporate culture into children's lives. Moreover, it identified how some foster parents promoted the cultural development of children and youth from racialized groups, within their homes and communities. Furthermore, this study captured the voices of foster parents, and drew on their experiences to provide information that can assist future foster parents, children in care, child protection agencies and researchers. By including the perspectives of foster parents, focused efforts can be made to meet the needs of children and youth from racialized groups, as well as foster parents involved in transcultural foster care placements.

The analysis, of the interviews with foster parents, revealed important and variable dynamics apparent within transcultural foster care placements. Accordingly, past personal experience, exposure to diverse communities, curiosity and the education of 
foster parents contributed to them being culturally receptive. Even foster parents, who held the view that a child from a racialized group is not any different than a child from a non-racialized group, went to great lengths to incorporate culture into children's lives.

Foster parent's cultural receptivity as well as their personal experience and exposure to a variety cultures significantly impacted the efforts they made to incorporate culture into their homes, as well as their daily activities. Additionally, it was evident foster parent's expended considerable amounts of personal energy to promote the cultural development of children and youth from racialized groups in their care. Interestingly, some foster parents still felt as though they were not doing enough and thought they should be doing more to promote the cultural development of children and youth from racialized groups. Foster parents, in this study, also indicated they refused to give up on pursuing what, they felt, was necessary to assist them in caring for children and youth from racialized groups.

Based on the findings of this study, it appears the current approaches used to educate foster parents about race and culture are less effective strategies to promote the cultural development of children and youth from racialized groups in their care. This suggests it would be more effective for child protection agencies to play an active role in providing resources, facilitating connections to culturally relevant community resources, and creating opportunities for foster parents to engage in discussions related to race and culture, as it relates to cultural development. In caring for children and youth from racialized groups, the child welfare field is called upon to initiate a collaborative relationship between foster parents, child protection agencies, biological families and community resources. By forming such a relationship, agencies may draw support and 
resources from each other to effectively identify and establish relationships with culturally relevant resources, to meet the needs of children and youth from racialized groups.

The findings, from this study, should encourage social workers to advocate for more funding, effective programs for foster parents before as well as during placements, additional staff to support the needs of foster parents, and additional resources for children and youth from racialized groups in care. The implications, this study provided, are useful to the child welfare and social work field, because they confirm that findings from other countries are present and relevant within the Canadian context. These implications also contribute to the gap in the existing literature, regarding cultural receptivity and how foster parents promote the cultural development, of children and youth from racialized groups, in Canada.

\section{Recommendations for Future Research}

This study was limited by a small sample size and a larger sample, including all the stakeholders within child welfare, may provide more generalizable conclusions. Future research is required to develop a consultative and collaborative process for working with child protection agencies, biological families, children and youth from racialized groups, foster parents as well as communities. Future research should include conversations with children and youth from racialized groups in foster care, as well as their biological families and members from their communities. Although foster parents shared their stories regarding promoting cultural development, this study did not include the voices of children and youth from racialized groups. A valuable contribution to the research literature would be a study that explores the conditions that promote and inhibit 
transmission of cultural knowledge and identity development, among children and youth from racialized groups.

Finally, a study that looks at the effects of transcultural foster care placements, as well as children's needs, from the perspectives of children and youth from racialized groups would be an important contribution to the existing literature. These conversations may provide additional insight into the types of policies, programs, resources, and support children and youth from racialized groups need to promote their cultural development. 


\section{References}

Audet, M., \& Home, A. (2004). Adopting special needs children: Parent's perception of their role quality and social support. In K. Kufeldt \& B. McKenzie (Eds.), Child welfare connecting research, policy, and practice (pp. 157-166). Waterloo, ON: Wilfred Laurier University Press.

Association of Black Social Workers Inc. (1989). Position statement: Placement issues concerning black children.

Baden, A., \& Steward, R. (2000). A framework for use with racially and culturally integrated families: The cultural-racial identity model as applied to transracial adoption. Journal of Social Distress \& the Homeless, 9(4), 309-337. doi:10.1023/A:1009493827019.

Baines, D. (Ed.). (2007). Doing anti-oppressive practice: Building transformative politicized social work. Black Point: Fernwood Publishing.

Barth, R. (1990). On Their Own: The experiences of youth after foster care. Child \& Adolescent Social Work Journal, 7(5), 419-440. Retrieved from SocINDEX with Full Text database.

Baum, B. D. (2006). The rise and fall of the Caucasian race: A political history of racial Identity. New York, NY: NYU Press.

Baum, A., Crase, S., \& Crase, K. (2001). Influences on the decision to become or not become a foster parent, Families in Society: The Journal of Contemporary Human Services 82(2): 202-13.213. Retrieved February 1, 2010, from Research Library. (Document ID: 72988751). 
Bernard, W., \& Este, D. (2005). Resiliency and young African Canadian males. In M. Ungar (Ed.), Handbook for working with children and youth: Pathways to resilience across cultures and contexts. (pp. 433-454). Thousand Oaks, CA: Sage Publications.

Better, S. (2008). Institutional racism: A primer on theory and strategies for social change ( $2^{\text {nd }}$ ed.). Lanham, MD: Rowman and Littlefield.

Bradley, C., \& Hawkins-León, C. (2002). The transracial adoption debate: Counselling and legal implications. Journal of Counselling \& Development, 80(4), 433-440.

Brown, C., \& Augusta-Scott, T. (Eds.) (2007). Narrative therapy: making meaning, making lives. Thousand Oaks, CA: Sage Publications.

Brown, J., \& Calder, P. (1999). Concept mapping the needs of foster parents. Child Welfare, 79(6), 729-746. Retrieved from Academic Search Premier database.

Brown, J., Sintzel, J., Arnault, D., \& George, N. (2009). Confidence to foster across cultures: Caregiver perspectives. Journal of Child \& Family Studies, 18(6), 633-642. doi:10.1007/s10826-009-9264-z.

Brown, J., St. Arnault, D., George, N., \& Sintzel, J. (2009). Challenges of transcultural placements: Foster parent perspectives. Child Welfare, 88(3), 103-126.

Burnette, D. (1999). Social relationships of Latino grandparent caregivers: A role theory perspective. The Gerontologist, 39(1), 49-58. Retrieved July 14, 2010, from Research Library. (Document ID: 38879268).

Cain, T. (2006). Reflections on My journey and social work education. In W. Thomas-Bernard (Ed.), Fighting for change: Black social workers in Nova Scotia (pp-114-124). East Lawrencetown: Pottersfield Press. 
Carter-Black, J. (2002). Transracial adoption and foster care placement: worker perception and attitude. Child Welfare League of America, 31 (2), 337-366. Retrieved March 22, 2010 from Academic Search Premier database.

Charmaz, K. (2006). Constructing grounded theory: A practical guide through qualitative analysis. London, UK: Sage Publications Ltd.

Child and Family Services Act (Nova Scotia).

Child, Family and Community Services Act (British Columbia).

Chipungu, S. \& Bent-Goodley, T. (2004). Meeting the challenges of contemporary foster care. The Future of Children, 14(1), 74-93. Retrieved March 5, 2010, from Research Library. (Document ID: 598472501).

Christenson, B., \& McMurtry, J. (2007). A comparative evaluation of preservice training of kinship and nonkinship foster/adoptive families. Child Welfare Journal, 86(2), 125-140. Retrieved from PsycINFO database.

Coakley, T., \& Buehler, C. (2008). Toward a theory of cultural competence in transcultural parenting: The role of cultural receptivity. Journal of Public Child Welfare, 2(4), 401425. doi:10.1080/15548730802523174.

Coakley, T., \& Orme, J. (2006). A psychometric evaluation of the cultural receptivity in fostering scale. Research on Social Work Practice, 16(5), 520-533. doi:10.1177/1049731506287080.

Creswell, J. (2007). Qualitative inquiry and research design: Choosing among five approaches $\left(2^{\text {nd }}\right.$ ed.). Thousand Oaks, CA: Sage Publications. 
Cross T., Bazron, B., Dennis, K., \& Isaacs, M. (1989). Towards a culturally competent system of care, volume I. Washington, DC: Georgetown University Child Development Center, CASSP Technical Assistance Center).

Dean, R. G. (2001). The myth of cross-cultural competence. Families in Society, 82(6), 623630. Retrieved April 5, 2010, from Research Library. (Document ID: 92759718).

de Haymes, M., \& Simon, S. (2003). Transracial adoption: families identify issues and needed support services. Child Welfare League of America, 32 (2), 251-272. Retrieved March 15, 2010 from Academic Search Premier database.

Denby, R., Rindfleisch, N., \& Bean, G. (1999). Predictors of foster parents' satisfaction and intent to continue to foster. Child Abuse \& Neglect, 23(3), 287-303. Retrieved from Academic Search Premier database.

Denby, R.W. \& Rindfleisch, N. (1996) ‘African Americans’ foster parenting experiences: Research findings and implications for policy and practice', Children and Youth Services Review 18(6): 525-54.

DeSouza, R. (2008). Wellness for all: The possibilities of cultural safety and cultural competence in New Zealand. Journal of Research in Nursing, 13(2), 125-135. doi:10.1177/1744987108088637.

DuMont, K., Widom, C., \& Czaja, S. (2007). Predictors of resilience in abused and neglected children grown-up: The role of individual and neighbourhood characteristics. Child Abuse \& Neglect, 31(3), 255-274. doi:10.1016/j.chiabu.2005.11.015.

Elliott, K., \& Urquiza, A. (2006). Ethnicity, culture, and child maltreatment. Journal of Social Issues, 62(4), 787-809. doi:10.1111/j.1540-4560.2006.00487.x. 
Faulkner, C.A., \& Faulkner, S.S. (2009). Research methods for social workers: A practicebased approach. Chicago, ILL: Lyceum Books Inc.

Floyd, J. Former foster care individuals' experiences of racial/cultural identity development: An exploratory study. Psy.D. dissertation, Rutgers The State University of New Jersey, Graduate School of Applied and Professional Psychology, United States -- New Jersey. Retrieved March 25, 2010, from Dissertations \& Theses: Full Text. (Publication No. AAT 3321861).

Freisthler, B., Bruce, E., \& Needell, B. (2007). Understanding the geospatial relationship of neighbourhood characteristics and rates of maltreatment for black, hispanic, and white children. Social Work, 52(1), 7-16. Retrieved from CINAHL with Full Text database.

Gibbs, D., \& Wildfire, J. (2007). Length of service for foster parents: Using administrative data to understand retention. Children \& Youth Services Review, 29(5), 588-599. doi:10.1016/j.childyouth.2006.11.002.

Harris. M. S., \& Hackett, W. (2008). Decision points in child welfare: An action research model to address disproportionality, Children and Youth Services Review 30 (2008), pp. 199-215. Available online at www.sciencedirect.com

hooks, B. (2004). We real cool Black men and masculinity. New York, NY: Routledge.

Kirton, D. (2001). Love and money: payment, motivation and the fostering task. Child \& Family Social Work, 6(3), 199-208. doi:10.1046/j.1365-2206.2001.00208.x.

Korbin, J. (2002). Culture and child maltreatment: cultural competence and beyond. Child Abuse \& Neglect, 26(6/7), 637. Retrieved from Academic Search Premier database. Krueger, M., \& Powell, N. (1990). Choices in caring: Contemporary approaches to child and youth care work. Washington, DC US: Child Welfare League of America. 
MacGregor, T., Rodger, S., Cummings, A., \& Leschied, A. (2006). The needs of foster parents: A qualitative study of motivation, support, and retention. Qualitative Social Work, 5(3), 351-368. doi:10.1177/1473325006067365.

Massatti, R. R., Vonk, M. E., \& Gregoire, T. K. (2004). Reliability and validity of the transracial adoption parenting scale. Research on Social Work Practice, 14, 43-50. Retrieved from SocINDEX with Full Text database.

MacGregor, T., Rodger, S., Cummings, A., \& Leschied, A. (2006). The needs of foster parents: A qualitative study of motivation, support, and retention. Qualitative Social Work, 5(3), 351-368. doi:10.1177/1473325006067365.

McGibbon, E.A., \& Etowa, J.B. (2009). Anti-racist health care practice. Toronto, ON: Canadian Scholars' Press Inc.

McGoldrick, M., \& Giordano, J. (1996). Preface. In M. McGoldrick, J.K. Pearce, \& J. Giordano (Eds.) Ethnicity and family therapy (2nd ed., pp. ix=xiii). New York, NY: Guilford.

McPhatter, A. (1997). Cultural competence in child welfare: What is it? How do we achieve it? What happens without it? Child Welfare, 76(1), 255-278. Retrieved from Academic Search Premier database.

Mederos, F., \& Woldeguiorguis, I. (2003). Beyond cultural competence: What child protection managers need to know and do? Child Welfare, 82(2), 125-142. Retrieved from Academic Search Premier database.

National Association of Black Social Workers. (2010). Retrieved from: http://www.nabsw.org/mserver/PreservingFamilies.aspx Parker, D., \& Song, M. (Eds.). (2001). Rethinking 'mixed race'. Sterling, VA: Pluto Press. 
Polaschek, N. (1998). Cultural safety: A concept in nursing people of different ethnicities. Journal of Advanced Nursing, 27 (3), 452-457. Retrieved from CINAHL with Full Text database.

Pon, G. (2009). Cultural competency as new racism: An ontology of forgetting. Journal of Progressive Human Services, 20(1), 59-71. doi:10.1080/10428230902871173.

Province of Nova Scotia. (2010). The process of becoming a Foster Parent. Retrieved from http://www.gov.ns.ca/coms/families/fostercare/BecomingaFosterParent.html

Rew, L., Becker, H., Cookston, J., Khosropour, S., \& Martinez, S. (2003). Measuring cultural awareness in nursing students. Journal of Nursing Education, 42(6), 249-257. Retrieved from CINAHL with Full Text database.

Rhodes, K., Orme, J., \& Buehler, C. (2001). A comparison of family foster parents who quit, consider quitting, and plan to continue fostering. Social Service Review, 75(1), 84-114. Retrieved from SocINDEX with Full Text database.

Rhodes, K. W., Orme, J. G., Cox, M. E., \& Buehler, C. (2003). Foster family resources, psychosocial functioning, and retention. Social Work Research, 27, 135-150. Retrieved from SocINDEX with Full Text database.

Richardson, F., \& Carryer, J. (2005). Teaching cultural safety in a New Zealand nursing education program. Journal of Nursing Education, 44(5), 201-208. Retrieved from CINAHL with Full Text database.

Rodger, S., Cummings, A., \& Leschied, A. (2006). Who is caring for our most vulnerable children?: The motivation to foster in child welfare. Child Abuse \& Neglect, 30(10), 1129-1142. doi:10.1016/j.chiabu.2006.04.005. 
Sakamoto, I. (2007). An anti-oppressive approach to cultural competence. Canadian Social Work Review, 24(1), 105-114. Retrieved from SocINDEX with Full Text database.

Strega, S. (2007). Anti-oppressive practice in child welfare. In D. Baines (Ed.), Doing antioppressive practice: Building transformative politicized social work (pp. 67-82). Black Point: Fernwood Publishing.

Super, C. M., \& Harkness, S. (1986). The developmental niche: A conceptualization at the interface of child and culture. International Journal of Behavioral Development, 9 545569.

Trocmé, N., Knoke, D., \& Blackstock, C. (2004). Pathways to the overrepresentation of Aboriginal children in Canada's child welfare system. Social Service Review, 78(4), 577-599. doi:10.1086/424545.

Twigg, R. (1991). The next step in foster care. Journal of Child \& Youth Care, 6(1), 79-85. Retrieved from PsycINFO database.

Twigg, R. (2009). Passion for those who care: What foster carers need. In S. McKay, D. Fuchs, \& I. Brown (Eds.), Passion for action in child and family services: Voices from the prairies (pp. 165-184). Regina, SK: Canadian Plains.

Tyebjee, T. (2003). Attitude, interest, and motivation for adoption and foster care. Child Welfare, 82(6), 685-706. Retrieved from CINAHL with Full Text database.

Vickers, J. (2002). The politics of "race": Canada, Australia and the United States. Ontario: Golden Dog Press.

Vonk, M. (2001). Cultural competence for transracial adoptive parents. Social Work, 46(3), 246-255. Retrieved from PsycINFO database. 
Vonk, M., \& Angaran, R. (2001). A pilot study of training adoptive parents for cultural competence. Adoption Quarterly, 4(4), 5-18. doi:10.1300/J145v04n04.

Williams, C. C. (2006). The epistemology of cultural competence. Families in Society, 87(2), 209-220,158. Retrieved April 5, 2010, from Research Library. (Document ID: 1037595211).

Wilson, K., Sinclair, L. \& Gibbs, I. (2000). The trouble with foster care: the impact of stressful events on foster carers. British Journal of Social Work, 30, 193-209.

Yee, J. Y., \& Dumbrill, G. (2003). Whiteout: Looking for race in Canadian social work practice. In A. Al-Krenawi \& J. R. Graham (Eds.), Multicultural social work in Canada (pp. 98-121). Don Mills, ON: Oxford University Press.

Zon, A., Lindeman, M., Williams, A., Hayes, C., Ross, D., \& Furber, M. (2004). Cultural safety in child protection: Application to the workplace environment and casework practice. Australian Social Work, 57(3), 288-298. doi:10.1111/j.1447-0748.2004.00147.x. 


\section{Appendix A Demographic Questionnaire}

1) Gender

Female

Male

Other

2) Age

19-29

30-39

40-49

50-59

$60+$

3) Highest level of education you have completed. If currently enrolled, mark the previous grade or highest degree received.

No schooling completed

Nursery school to $8^{\text {th }}$ grade

$9^{\text {th }}, 10^{\text {th }}$, or $11^{\text {th }}$ grade

$12^{\text {th }}$ grade, no diploma

High school graduate-diploma or equivalent (i.e. GED)

College diploma or certificate program

Bachelor's degree

Graduate degree

Professional degree

Doctorate degree

None of the above (please describe)

4) Employment status

Do you work outside the home? _ Yes__No Full time_ Part time

If yes, please describe your work.

5) Annual household income

Less than $\$ 10,000$

$\$ 10,000$ to 29,999

$\$ 30,000$ to 49,999

$\$ 50,000$ to 69,999

$\$ 70,000$ to 89,999

$\$ 90,000$ to 149,999

_\$150, 000 or more 
6) Relationship Status

_ Single

Married

Same sex couple

Live in couple

Check all that apply

7) Which heritage group do you belong to? (Please check all that apply)

Aboriginal/First Nations

Asian (Chinese, Japanese, etc.)

Black (African, Caribbean, etc.)

Latino (Mexican, Puerto Rican, etc.)

Middle Eastern (Arab, Persian, Turk etc.)

South Asian (East Indian, Pakistani, etc.)

South East Asian (Vietnamese, Filipino, etc.)

White (European, etc.)

Mulitracial (please describe)

None of the above (please describe)

a. If there is a more specific group(s) that you identify with (i.e. Jewish, Jamaican, etc.) please describe

b. If you have a live in partner please indicate which heritage group they belong to (Please check all that apply)

Aboriginal/First Nations

Asian (Chinese, Japanese, etc.)

Black (African, Caribbean, etc.)

Latino (Mexican, Puerto Rican, etc.)

Middle Eastern (Arab, Persian, Turk etc.)

South Asian (East Indian, Pakistani, etc.)

South East Asian (Vietnamese, Filipino, etc.)

White (European, etc.)

Multiracial(please describe)

_None of the above (please describe)

c. If there is a more specific group(s) that your partner would identify with (i.e. Jewish, Jamaican etc.) please describe

8) How long have you been a foster parent?

years months days

9) Approximately, how many children have you fostered during your time as a foster parent? 
10) How many children or youth of colour, in care, currently reside in your home?

a. What are the ages of these children or youth?

b. Approximately how many children or youth of color have resided in your home during the time you have been a foster parent?

c. Do you have any children other than the children you provide foster care for? If yes, please list their ages. 


\section{Appendix B Interview Guide}

1) How has the training you received prepared you for fostering children and youth of color?

(a) What did you find the most helpful?

(b) If you found it was not helpful what suggestions would you make to improve the training based on your experiences?

2) What does it mean to you to be culturally receptive?

3) During your time as a foster parent, what are some things you have done to increase your knowledge and understanding of culturally distinct groups?

4) Does your family participate in any cultural events? Which ones?

5) What do you do in your home to promote the cultural development of children and youth of color in your care?

6) How has having children of color, in your home, affected you and your family?

7) What has been the most challenging about fostering children and youth of color?

8) What supports are available in the community that will support the cultural development of the children and youth of color in your care?

9) Are you comfortable seeking out these supports? If no, what would make you more comfortable?

10) What opportunities do you have available to you to provide children and youth of color with the chance to establish relationships with people from their birth culture?

11) What supports do you have available to you to deal with overt (direct) or covert (indirect) acts of racism towards the children and youth of color in your care?

12) From your experience, what sorts of things have limited your ability to promote the cultural development of the children and youth of color in your care?

13) What advice would you offer other foster parents involved in transcultural foster arrangements?

14) What would you like to add about your experience as a foster parent caring for children and youth of color? 